\title{
Multidecadal Changes of the Upper Indian Ocean Heat Content during 1965-2016 0
}

\author{
YUANLONG LI \\ Key Laboratory of Ocean Circulation and Waves, Institute of Oceanology, Chinese Academy of Sciences, Qingdao, \\ China, and Department of Atmospheric and Oceanic Sciences, University of Colorado Boulder, Boulder, Colorado, \\ and Function Laboratory for Ocean Dynamics and Climate, Qingdao National Laboratory for Marine Science \\ and Technology, Qingdao, China
}

\section{WEIQING HAN}

Department of Atmospheric and Oceanic Sciences, University of Colorado Boulder, Boulder, Colorado

\author{
Aixue Hu And Gerald A. MeEhl \\ National Center for Atmospheric Research, Boulder, Colorado
}

\section{FAN WANG}

Key Laboratory of Ocean Circulation and Waves, Institute of Oceanology, Chinese Academy of Sciences, and Function Laboratory for Ocean Dynamics and Climate, Qingdao National Laboratory for Marine Science and Technology, and Center for Ocean Mega-Science, Chinese Academy of Sciences, Qingdao, China

(Manuscript received 28 February 2018, in final form 5 June 2018)

\begin{abstract}
Ocean heat uptake is the primary heat sink of the globe and modulates its surface warming rate. In situ observations during the past half century documented obvious multidecadal variations in the upper-ocean heat content $\left(0-400 \mathrm{~m} ; \mathrm{OHC}_{400}\right)$ of the Indian Ocean (IO). The observed $\mathrm{OHC}_{400}$ showed an increase of $(5.9 \pm 2.5) \times 10^{21} \mathrm{~J}_{\text {decade }}^{-1}$ during $1965-79$, followed by a decrease of $(-5.2 \pm 2.5) \times 10^{21} \mathrm{~J} \mathrm{decade}^{-1}$ during $1980-96$, and a rapid increase of $(13.6 \pm 1.1) \times 10^{21} \mathrm{~J} \mathrm{decade}^{-1}$ during $2000-14$. These variations are faithfully reproduced by an Indo-Pacific simulation of an ocean general circulation model (OGCM), and insights into the underlying mechanisms are gained through OGCM experiments. The Pacific wind forcing through the Indonesian Throughflow (ITF) was the leading driver of the basin-integrated $\mathrm{OHC}_{400}$ increase during 1965-79 and the decrease during 1980-96, whereas after 2000 local wind and heat flux forcing within the IO made a larger contribution. The ITF heat transport is primarily dictated by Pacific trade winds. It directly affects the south IO, after which the signatures can enter the north IO through the meridional heat transport of the western boundary current. The prevailing warming of the western-tocentral IO for 2000-14 was largely induced by equatorial easterly wind trends, Ekman downwelling off the equator, and northeasterly wind trends over the west Asia-East Africa coastal region. The increasing downward longwave radiation, probably reflecting anthropogenic greenhouse gas forcing, overcame the decreasing surface shortwave radiation and also made a significant contribution to the rapid upper-IO warming after 2000.
\end{abstract}

Supplemental information related to this paper is available at the Journals Online website: https://doi.org/10.1175/JCLI-D-180116.s1.

Corresponding author: Yuanlong Li, liyuanlong@qdio.ac.cn

\section{Introduction}

\section{a. Indian Ocean heat content and impact}

The ocean heat content (OHC) changes account for more than $90 \%$ of the changes in the globe's energy budget (e.g., Trenberth and Fasullo 2010, 2012) and 
significantly modulate the pace at which the global mean surface temperature (GMST) is rising. The recent slowdown of GMST warming during the early twenty-first century, dubbed the "hiatus" (e.g., Easterling and Wehner 2009; Meehl et al. 2011; Trenberth and Fasullo 2013), has been attributed to the increased subsurface ocean heat uptake by the majority of the research community (e.g., Chen and Tung 2014; Roemmich et al. 2015; Xie 2016; Liu et al. 2016). Owing to its smaller area than the Pacific and the Atlantic, the importance of the Indian Ocean (IO) in the global ocean heat budget was not recognized until the recent hiatus period, during which the abrupt increase of upper-IO heat content served as a major sink of the excessive heat entering the Earth system (Cheng et al. 2015; Nieves et al. 2015; Lee et al. 2015).

In December 2015, the Paris Agreement of the United Nations Framework Convention on Climate Change (UNFCCC) agreed to pursue efforts to limit the GMST increase within $1.5 \mathrm{~K}$ above preindustrial levels (UNFCCC Conference of the Parties 2015). Scientific efforts in understanding $\mathrm{OHC}$ changes are helpful for reducing the uncertainties in policy making. In addition, the enhanced warming of the upper IO (Lee et al. 2015; Li et al. 2017) has brought many serious impacts to the regional climate and environment, such as weakening of the South Asian monsoon due to the decreasing land-sea thermal contrast (e.g., Bollasina et al. 2011; Roxy et al. 2015; Singh 2016), reduction in marine primary productivity (Roxy et al. 2016), frequent disastrous marine heatwave and coral bleaching events (Wernberg et al. 2013; Feng et al. 2015; Zinke et al. 2015), and increased stress of sea level rise in low-lying coastal areas and island nations (Han et al. 2010; Nicholls and Cazenave 2010). Consequently, quantifying and understanding the upper-IO heat content variations in the observed history are of scientific and practical significance.

\section{b. Decadal-to-multidecadal variability of the upper IO}

Decadal ( $~ 10 \mathrm{yr}$ )-to-multidecadal ( $>10 \mathrm{yr}$ ) variations of the upper IO are controlled by complex mechanisms involving local climate processes versus remote forcing from other ocean basins, dynamic versus thermodynamic processes, and natural climate variability versus anthropogenic effects (e.g., Allan et al. 1995; Schott et al. 2009; Han et al. 2014). Among the various factors, the interdecadal Pacific oscillation (IPO; Power et al. 1999) exerts a strong influence on the IO. Wind anomalies associated with the IPO drive oceanic waves that are able to transmit through the Indonesian channels (Clarke and Liu 1994; Meyers 1996), modulating the heat transport of the Indonesian Throughflow (ITF; Wijffels and Meyers 2004; Cai et al. 2005; Nidheesh et al. 2013; Sprintall et al. 2014) and causing upper-ocean variations in the south IO (Feng et al. 2004, 2013, 2015; Schwarzkopf and Böning 2011; Li et al. 2017; Ummenhofer et al. 2017). The negative IPO condition, with La Niña-like sea surface temperature (SST) anomalies and enhanced trade winds over the tropical Pacific, strengthens the ITF heat transport and results in rapid warming of the IO (England et al. 2014; Nieves et al. 2015; Lee et al. 2015), and meanwhile leads to decelerated GMST warming, such as for the cases of the "big hiatus" of the 1940-70s and the early twenty-first-century hiatus (Kosaka and Xie 2013, 2016; Meehl et al. 2014, 2016). The positive IPO condition, with frequently occurring strong El Niños, leads to cooling of the IO and accelerated GMST warming, such as for the period of the 1970s-90s.

Besides the oceanic connection, climate variability in other ocean basins can also affect the IO via the atmospheric bridge. El Niño-Southern Oscillation (ENSO) and IPO can induce large-scale anomalies of surface winds, heat fluxes, and rainfall over the IO (Klein et al. 1999; Alexander et al. 2002; Lee and McPhaden 2008). Meanwhile, climate modes of the Atlantic Ocean such as the Atlantic multidecadal oscillation (AMO) may also modulate the tropical IO climate via atmospheric teleconnection ( $\mathrm{Li}$ et al. 2016). These external impacts are entangled with the IO local climate variability, with both causing variability in the upper IO (Lee 2004; Alory et al. 2007; Han et al. 2010; Trenary and Han 2013; Nieves et al. 2015). Regardless of different origins, in this study we do not distinguish the two forcing effects and collectively refer to them as "local atmospheric forcing effects within the IO." Recent studies suggest that local atmospheric forcing effects, particularly those associated with natural internal climate variability, are responsible for most of the decadal variations of the upper IO (Han et al. 2006, 2010, 2017b; Trenary and Han 2013; Li and Han 2015). Stochastic atmospheric forcing, such as the tropical atmospheric intraseasonal oscillations (ISOs) and midlatitude storm tracks (Sura et al. 2006), can also cause decadal ocean variability. This effect, however, is shown to be important only in the subtropical southwest IO ( $\mathrm{Li}$ and Han 2015). Anthropogenic forcing is another origin for the IO heat content variability, particularly for the multidecadal trend. The increased anthropogenic greenhouse gas concentration causes SST warming of the IO through surface longwave radiation (Du and Xie 2008; Dong et al. 2014; Zhang et al. 2018). Meanwhile, the increased anthropogenic aerosols over Asia in the past several decades and aerosols from volcanic eruptions (Gleckler et al. 2006; Smith et al. 2016) can cause SST cooling of the IO (Cai et al. 2006, 2007; Dong and Zhou 2014).

Besides atmospheric forcing, ocean internal instabilities, manifesting as mesoscale eddies and current meanders, can also cause significant decadal-to-multidecadal 
variability in some regions because of nonlinearity of the oceanic system. Modeling studies suggest that in eddyrich areas of the IO-for example, the subtropical south IO, the Somali Current region, and the western Bay of Bengal-low-frequency oceanic variability induced by ocean internal instability is comparable in strength to that induced by atmospheric forcing (e.g., Wirth et al. 2002; Trenary and Han 2013; Li and Han 2015; Sérazin et al. 2016). Since ocean internal instabilities are generally unpredictable for ocean/climate models, they cause significant uncertainties for decadal ocean prediction.

\section{c. The present study}

Given the complexity of the problem, a thorough investigation is imperative for quantifying and understanding the upper-IO heat content variations in the observed history and thereby providing theoretical support for future prediction, policy making, and adaptation of human societies. This effort is pursued in the present study by analyzing historical ocean observational data and performing ocean general circulation model (OGCM) experiments that are capable of isolating effects from different processes. Our results show strikingly strong multidecadal changes of the upper-IO heat content. The decadal trends of the IO heat content in $0-400 \mathrm{~m}\left(\mathrm{OHC}_{400}\right)$ reached as large as $O\left(10^{22}\right)$ $\mathrm{J}_{\text {decade }}{ }^{-1}$, on the same order of the global OHC changes (Chen and Tung 2014; Roemmich et al. 2015; Cheng et al. 2017) and are potentially influential for global climate change. The roles played by major processes, such as ITF heat transport due to Pacific wind forcing, local wind forcing, and radiation forcing within the IO, are examined.

The remainder of the paper is arranged as follows. In section 2, we introduce observational datasets, describe the OGCM utilized in this study, and design a hierarchy of OGCM experiments. In section 3, we describe the observed and simulated multidecadal $\mathrm{OHC}_{400}$ variations and verify the performance of the OGCM. In section 4 , we expound the mechanisms controlling the multidecadal $\mathrm{OHC}_{400}$ variability by assessing the relative importance of different processes. In section 5 , we provide a summary and discussion for our primary findings.

\section{Data and model}

\section{a. Datasets}

To estimate $\mathrm{OHC}_{400}$ variability, four ocean subsurface temperature datasets are analyzed and compared: 1) the World Ocean Atlas (WOA; Levitus et al. 2009) during 1955-2016 provided by the National Oceanic and Atmospheric Administration (NOAA)'s National Centers for Environmental Information (NCEI) of the
United States, 2) the Ishii data (Ishii et al. 2005) during 1955-2012 from the Frontier Research System for Global Change, the Japan Agency for Marine-Earth Science and Technology (JAMSTEC), 3) the EN4.2.0 data (Good et al. 2013) during 1955-2016 provided by the Met Office, and 4) the Institute of Atmospheric Physics (IAP) ocean temperature analysis (Cheng et al. 2016, 2017) during 1955-2015 provided by the IAP, Chinese Academy of Sciences (CAS). All the four products provide $1^{\circ} \times 1^{\circ}$, standard-level, annual temperature estimates in the upper $700 \mathrm{~m}$. Since large discrepancies exist among the four products in some regions (Wang et al. 2018), we consider the consensus of the four products as the "observational fact" and their spread as observational uncertainty. In addition, two versions of Simple Ocean Data Assimilation (SODA) products (Carton et al. 2005; Carton and Giese 2008) are also analyzed. SODA2.2.4 (SODA2) is forced with NOAA Twentieth Century Reanalysis, version 2 (20CR V2; Compo et al. 2011), and has an average resolution of $0.25^{\circ} \times 0.4^{\circ} \times 40$ levels, covering 1871-2010, while SODA3.3.1 (SODA3) is forced by Modern-Era Retrospective Analysis for Research and Applications, version 2 (MERRA-2; Rienecker et al. 2011 ), and has a resolution of $0.25^{\circ} \times 0.25^{\circ} \times 50$ levels, covering the span of 1980-2015.

$\mathrm{OHC}_{400}$ is used to quantify the upper-IO heat uptake, and for each dataset it is computed as

$$
\mathrm{OHC}_{400}=\int_{-400 \mathrm{~m}}^{0} \rho C_{p} T d z
$$

where $T$ is ocean temperature, and $\rho$ and $c_{p}$ are density and thermal capacity of seawater. The $0-400 \mathrm{~m}$ is defined as the "upper ocean" based on two considerations: the main thermocline of the tropical-to-subtropical IO resides roughly between the 100- and 300-m range (e.g., Schott et al. 2009; Li and Wang 2015), and therefore strong signatures of baroclinic ocean waves are confined above $400 \mathrm{~m}$, and the upper $400 \mathrm{~m}$ shows prominent decadal-to-multidecadal thermal variations and is strongly affected by natural climate modes (Cheng et al. 2015; Li et al. 2017), while the intermediate-to-deep IO shows monotonic warming owing to anthropogenic effects (Chen and Tung 2014; Liu et al. 2016). In this study, the IO is defined within the Australia-Asia-Africa coastline, north of $35^{\circ} \mathrm{S}$ and west of $125^{\circ} \mathrm{E}$. The Red Sea, Persian Gulf, and Indonesian Seas are excluded from the $\mathrm{OHC}_{400}$ integration.

To evaluate the OGCM solution, we also used $0.25^{\circ} \times$ $0.25^{\circ}$ monthly satellite sea level data based on the satellite altimeter sea surface height (SSH) product from the Archiving, Validation, and Interpretation of Satellite Oceanographic Data (AVISO) from January 1993 
through August 2016 (Le Traon et al. 1998), and $1^{\circ} \times 1^{\circ}$ monthly latent and sensible heat fluxes of the objectively analyzed air-sea fluxes (OAFlux) from 1958 through 2016 (Yu and Weller 2007). To quantify the IPO-relevant climate variability and examine its relationship with the Indian $\mathrm{OHC}_{400}$ changes, the IPO index is computed with the monthly Hadley Centre Sea Ice and Sea Surface Temperature dataset (HadISST) from 1871 through 2016 (Rayner et al. 2003), adopting the "tripole" index method of Henley et al. (2015), that is, the SST anomaly difference between the equatorial Pacific $\left(10^{\circ} \mathrm{S}-10^{\circ} \mathrm{N}, 170^{\circ} \mathrm{E}-90^{\circ} \mathrm{W}\right)$ and the northwest plus southwest Pacific region $\left(140^{\circ} \mathrm{E}-\right.$ $145^{\circ} \mathrm{W}, 25^{\circ}-45^{\circ} \mathrm{N}$ plus $\left.150^{\circ} \mathrm{E}-160^{\circ} \mathrm{W}, 50^{\circ}-15^{\circ} \mathrm{S}\right)$. In addition to ocean datasets, five surface wind reanalysis products are analyzed and compared: 1 ) the $0.75^{\circ}$ European Centre for Medium-Range Weather Forecasts (ECMWF) interim reanalysis (ERA-Interim) from 1979 to 2016 (Dee et al. 2011), 2) the $1^{\circ}$ ECMWF Twentieth Century Reanalysis (ERA-20C) from 1955 to 2010 (Poli et al. 2016), 3) the $1.875^{\circ}$ National Centers for Environmental Prediction-National Center for Atmospheric Research (NCEP-NCAR) from 1955 to 2016 (Kalnay et al. 1996), 4) the $0.5^{\circ} \times 0.625^{\circ}$ MERRA-2 winds from 1980 to 2016, and 5) the $1^{\circ}$ Climate Forecast System Reanalysis (CFSR) from 1979 to 2016 (Saha et al. 2010).

\section{b. HYCOM}

The OGCM used in this study is the Hybrid Coordinate Ocean Model (HYCOM), version 2.2.18 (Halliwell 2004), configured to the Indo-Pacific Ocean basin between $19^{\circ} \mathrm{E}-68^{\circ} \mathrm{W}$ and $55^{\circ} \mathrm{S}-50^{\circ} \mathrm{N}$ (see Fig. S1 in the online supplementary material). The zonal resolution is $1 / 3^{\circ}$ between $70^{\circ}$ and $170^{\circ} \mathrm{E}$ and gradually changes to $1^{\circ}$ west of $40^{\circ} \mathrm{E}$ and east of $160^{\circ} \mathrm{W}$, while the meridional resolution is $13^{\circ}$ at low latitudes $\left(25^{\circ} \mathrm{S}-25^{\circ} \mathrm{N}\right)$ and gradually changes to $1^{\circ}$ at midlatitudes (poleward of $\sim 44^{\circ}$ ). The model has 35 hybrid vertical layers, with a top layer thickness of $5 \mathrm{~m}$. On the open-ocean boundaries of the model domain, $5^{\circ}$ sponge layers are applied wherein model temperature and salinity are relaxed to World Ocean Atlas 2013 (WOA13) monthly climatology (Locarnini et al. 2013; Zweng et al. 2013). The surface atmospheric forcing fields include surface wind stress, $10-\mathrm{m}$ wind speed, shortwave and longwave radiation (SWR and LWR), precipitation, and 2-m air temperature and humidity, which are taken from ERA-20C and ERA-Interim. Monthly climatologic river discharges of Dai et al. (2009) are used as lateral freshwater flux forcing. To suppress the drifting of model salinity, sea surface salinity is relaxed to WOA13 climatology with an $e$-folding time of $\sim 135$ days. Wind stress and wind speed are imposed separately on the model ocean and affect ocean temperature through different processes. Wind stress drives ocean dynamics (advection and upwelling) and mixing, while wind speed affects ocean temperature mainly through surface turbulent heat flux (latent plus sensible heat fluxes). In our model, turbulent heat fluxes and evaporation are calculated online with wind speed, air temperature, specific humidity, and modeled SST using the Coupled Ocean-Atmosphere Response Experiment, version 3.0 (COARE 3.0) algorithm (Fairall et al. 2003; Kara et al. 2005).

The model was spun up for 30 years, using monthly climatologic fields of ERA-20C as surface forcing. Subsequent to the spinup run, the model is integrated forward from 1940 to 2016 in three parallel experiments. The "main run" (MR) is forced by daily ERA-20C fields for 1940-2010 and daily ERA-Interim fields for 2011-16. ERA-20C and ERA-Interim are highly consistent with each other in surface winds during their overlapping period but show discrepancies in surface radiations (figures not shown). To reduce the effect of discontinuity in radiation forcing, LWR and SWR of ERAInterim are tuned toward those of ERA-20C in annual mean climatology. MR contains the complete processes of the Indo-Pacific Ocean and is compared with observational data to evaluate the model performance.

The second experiment is the "Pacific run" (PAC), in which daily forcing is retained in the Pacific (the same as in MR), whereas monthly climatologic forcing (retaining only seasonal cycle) is imposed on the IO (Fig. S1b). There is a $5^{\circ}$ transition zone where daily forcing outside the IO gradually changes to climatologic forcing. As such, the IO variability in the PAC is primarily induced by the Pacific Ocean variability through the ITF. The Southern Ocean may also affect the IO, but this effect is small in PAC because only a small part of the Antarctic Circumpolar Current is included in our model configuration. The difference between MR and PAC, that is, MR - PAC, can roughly represent the total effect of local atmospheric forcing within the IO (including both local climate variability and atmospheric teleconnections from other basins). It should be stated that the Pacific forcing effect and local forcing effect may not be clearly separable in such linear sense. As one of the reviewers pointed out, a more solid method is to perform an "Indian Ocean run" to assess the local forcing effect and analyze its results with those of MR and PAC to assess separately the two effects along their interaction. This has not been done because of the availability of computation resources.

The third experiment, the "wind stress run" (TAU), provides insights from another perspective. TAU is forced with daily wind stress, whereas other forcing fields, such as wind speed, radiation, and precipitation, are fixed to monthly climatology. As such, TAU roughly represents 

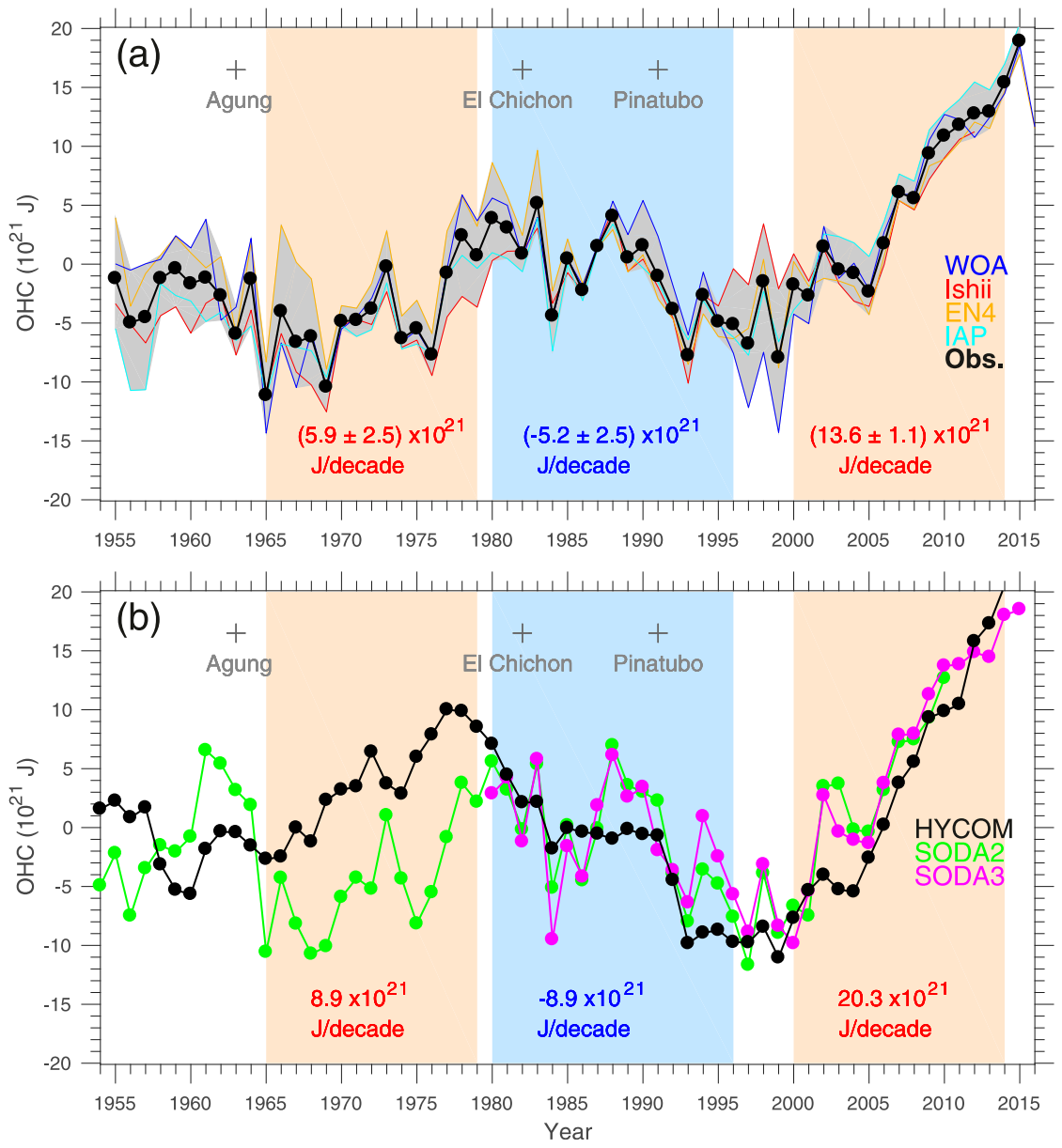

FIG. 1. (a) Time series of annual ocean heat content of $0-400 \mathrm{~m}\left(\mathrm{OHC}_{400}\right)$ integrated over the IO, derived from WOA, Ishii, EN4, IAP, and their average (referred to as observations; black dotted line). Gray shading denotes spread of the four datasets. Linear trends are estimated for the periods of 1965-79, 1980-96, and 2000-14. (b) As in (a), but derived from SODA2, SODA3, and HYCOM MR. Trends are estimated for HYCOM MR. Each variable is shown as an anomaly relative to the 1980-2010 mean value. Volcano eruptions of 1973 Mount Agung, 1982 El Chichón, and 1991 Mount Pinatubo are marked with "+."

the effect of wind stress-driven ocean dynamics (hereafter "wind-forcing effect"), and the difference between MR and TAU, that is, MR - TAU, mainly assesses the effect of surface heat fluxes (SWR, LWR, and turbulent heat flux) on the IO heat content. Outputs of the three experiments during 1940-2016 were stored in monthly mean resolution and further averaged into annual mean fields for our analysis. Isopycnal-coordinate HYCOM data were interpolated to 10 -m-depth intervals to facilitate the computation of $\mathrm{OHC}_{400}$.

\section{Multidecadal variations of the IO heat content}

Time series of annual Indian $\mathrm{OHC}_{400}$ from observation is shown in Fig. 1a. Despite strong interannual fluctuations, multidecadal variations stand out as the most striking feature in the documented history since the 1950s. Four datasets reach consensus over the periods of 1965-79, 1980-96, and 2000-14, during which $\mathrm{OHC}_{400}$ exhibited increasing, decreasing, and increasing trends, respectively. During $1965-79, \mathrm{OHC}_{400}$ showed a linear trend of $(5.9 \pm 2.5) \times 10^{21} \mathrm{~J} \mathrm{decade}^{-1}$ (where the error denotes the standard deviation of the trends estimated from different datasets), with the maximum trend detected by WOA and the minimum detected by Ishii. The interproduct discrepancy is rather large until the early 1980s. EN4 data showed a warmer IO for 1966-68 compared to the other three products, and WOA and EN4 were warmer than Ishii and IAP for 1977-82, possibly because of the different processing/correction procedures of the expendable bathythermograph (XBT) data in the four products (Cheng et al. 2016). In the 
subsequent period of $1980-96, \mathrm{OHC}_{400}$ decreased at a rate of $(-5.2 \pm 2.5) \times 10^{21} \mathrm{~J} \mathrm{decade}^{-1}$, with the largest (smallest) decreasing trends derived from EN4 (Ishii). The discrepancies mainly arise in 1980-82 and 1996. In the early twenty-first century, an enhanced warming was observed in all products, with an increasing rate of $(13.6 \pm 1.1) \times 10^{21} \mathrm{~J} \mathrm{decade}^{-1}$. The maximum trend is obtained from IAP, with the minimum again obtained from Ishii. It is noteworthy that this rapid Indian $\mathrm{OHC}_{400}$ increase has reached the same order of magnitude as the global $\mathrm{OHC}$ variability $\left[O\left(10^{22}\right) \mathrm{J} \mathrm{decade}^{-1}\right]$ (Chen and Tung 2014; Roemmich et al. 2015; Cheng et al. 2017), and therefore may have played a crucial role in regulating the GMST warming rate-particularly the recent hiatus-by storing a large amount of heat in the subsurface IO. Compared to the previous two periods, the discrepancy is significantly reduced during the post-2000 period, likely because of the contribution of Argo floats that greatly improved the sampling of the subsurface ocean. Note that here the three periods are chosen to capture continuous warming/ cooling tendencies of the upper IO, instead of according to the transitions of IPO phase. The periods of 1955-64 and 1997-99 are not analyzed, since the interproduct spread is too large to determine the trend sign with consensus. The years 2015 and 2016 are excluded from the third period despite the continued warming in 2015. These two years were subjected to the influence of strong El Niño and are discussed separately in section 5 .

The observed multidecadal changes of the Indian $\mathrm{OHC}_{400}$ are well reproduced by HYCOM MR and SODA (Fig. 1b). The linear trends estimated from MR are respectively $8.9,-8.9$, and $20.3 \times 10^{21} \mathrm{~J} \mathrm{decade}^{-1}$ for the three periods, evidently stronger than observational estimates. SODA3 shows a warming trend of $17.3 \times 10^{21} \mathrm{~J} \mathrm{decade}^{-1}$ during 2000-14, also larger than observations. Considering the $\sim 2.0 \times 10^{21} \mathrm{~J}$ standard deviation of interannual variability (estimated with the detrended annual $\mathrm{OHC}_{400}$ for each period), the differences between model and reanalysis results in decadal trends are significant. It is possible that some strong warming and cooling signals, especially those in coastal areas, are not resolved by observations because of lack of records, and thus likely underestimated in observationbased datasets. On the other hand, model errors and uncertainties in surface forcing fields can also cause model/data differences. Indeed, reanalysis products show considerable discrepancies in air-sea fluxes over the IO (e.g., Han et al. 2010, 2017a; Liang and Yu 2016). In addition, ocean internal variability may also contribute to the overestimation of decadal $\mathrm{OHC}_{400}$ changes in MR, which will be discussed in section $4 \mathrm{a}$.
Spatial distributions of these warming and cooling trends are also of interest. Figure 2 shows $T_{400}$ (average temperature of $0-400 \mathrm{~m}$ ) trend patterns for the three periods. During 1965-79, significant warming occurred in the subtropical south IO (Fig. 2a), with enhanced signals in the southern basin, and this pattern is reasonably reproduced by HYCOM MR (Fig. 2d). During 1980-96, an overall cooling of the IO occurred in both observation and MR (Figs. 2b,e). However, the observed cooling trends are concentrated in the central equatorial region, whereas in HYCOM those are more evident in the eastern basin including the Bay of Bengal. Checking trend patterns of individual datasets (WOA, Ishii, EN4, IAP, and SODA3) suggests broad agreements, with also obvious discrepancies (Fig. S2). The enhanced cooling of the central equatorial IO is seen in $W O A$, EN4, and SODA3 but not in Ishii and IAP, and EN4 and IAP also show cooling in the eastern equatorial IO and Bay of Bengal. During 2000-14, prevailing warming occurred throughout the basin (Fig. 2c). Stronger warming signals $>0.3 \mathrm{~K} \mathrm{decade}^{-1}$ were observed in the central-to-western north IO and subtropical south IO, and a cooling occurred in the subtropical southwest IO. This spatial distribution is also captured by MR, albeit with prevailingly larger magnitudes (Fig. 2f). HYCOM produces strong and significant warming in the tropical southwest IO, which are, however, weak and insignificant in observational datasets, although some of the signals are also seen in SODA3 (Fig. S2). These model errors should be noticed in the following analysis. SODA products also show evidently stronger trend signals than observation, in a similar manner as HYCOM.

Given the insufficient sampling of subsurface in situ data, satellite SSH observation can be used for further validation of HYCOM performance. MR is able to realistically simulate the climatologic distribution of $\mathrm{SSH}$ (Figs. 3a,b) and its variability in different areas of the IO (Figs. 3c-f). Here we choose four regions covering strong decadal variability of the IO as revealed by previous studies (e.g., Trenary and Han 2013; Nidheesh et al. 2013; Zhuang et al. 2013; Li and Han 2015), which are ideal areas for testing the model fidelity. The linear correlations between MR and AVISO monthly in SSH anomaly are $0.87,0.89,0.93$, and 0.88 for the southwest tropical IO (Fig. 3c), the Bay of Bengal (Fig. 3d), the southeast IO (Fig. 3e), and the subtropical south IO (Fig. 3f), respectively. Existing studies suggest that decadal SSH variations in these regions are dictated by different processes: local wind forcing dominates the southwest tropical IO and the Bay of Bengal; heat flux forcing plays a vital role in the subtropical south IO; and remote forcing of the Pacific trade winds and freshwater flux are important in the southeast IO (e.g., Feng et al. 

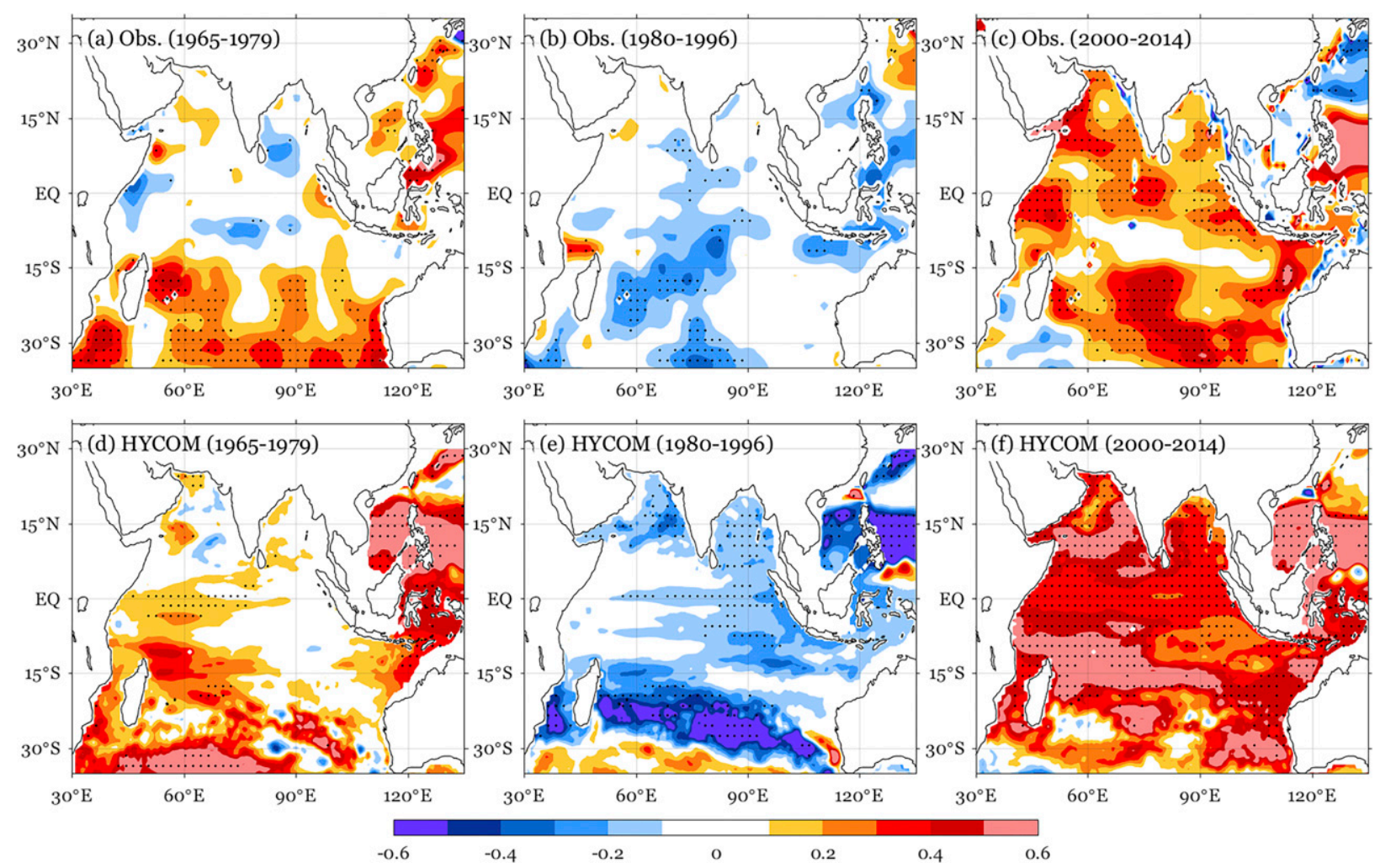

FIG. 2. Trend maps of 0-400-m mean temperature $T_{400}\left(\mathrm{~K}\right.$ decade $\left.^{-1}\right)$ for (a) 1965-79, (b) 1980-96, and (c) $2000-14$ derived from observations (the average of four observational datasets). (d)-(f) As in (a)-(c), but based on HYCOM MR. Stippling indicates exceeding $95 \%$ significance determined by a Mann-Kendall test.

2004; Trenary and Han 2013; Nidheesh et al. 2013; Li and Han 2015; Llovel and Lee 2015; Li et al. 2017). The fidelity of the simulated sea surface height anomaly (SSHA) in these regions indicates that HYCOM is able to realistically represent the upper-IO processes induced by various forcing fields and is thus suitable for mechanism exploration of the $\mathrm{OHC}_{400}$ variability.

\section{Processes causing the $\mathrm{OHC}$ variations}

\section{a. Relative importance of different processes}

This section explores the physical processes causing multidecadal $\mathrm{OHC}_{400}$ variations. First, we examine the relative importance of remote forcing from the Pacific via the ITF versus local forcing over the IO (Figs. 4a,b). PAC (Figs. 4a,b, blue) explains a large portion of the decadal $\mathrm{OHC}_{400}$ variations in $\mathrm{MR}$, accounting for $\sim 90 \%$ of the total $\mathrm{OHC}_{400}$ increase of 1965-79, and showed even larger decreasing trend during 1980-96. However, during 2000-14, the Pacific-origin warming explained merely $\sim 44 \%$ of the total, and it was slightly larger than that of $1965-79\left(9.1\right.$ vs $\left.8.1 \times 10^{21} \mathrm{~J} \mathrm{decade}^{-1}\right)$. On the other hand, the difference between MR and PAC
(MR - PAC) quantifies local atmospheric forcing effect in the IO. This effect had little contribution to the first two periods but played the major role $(\sim 56 \%)$ in the post-2000 warming. This means that the mechanism is likely varying with time, with increasing importance of IO local processes in the twenty-first century.

To assess the effects of wind versus heat flux forcing, we analyze the solutions of TAU and MR (Figs. 4c,d). The wind stress-driven ocean dynamics, as measured by TAU, play a fundamental role in modulating $\mathrm{OHC}_{400}$ variability. Their contributions are large for all three periods. Particularly during $1965-79$ and 2000-14, TAU explained more than half of the total $\mathrm{OHC}_{400}$ increasing trend. MR - TAU roughly represents the heat flux forcing effect, which also made large contributions. The wind stress forcing effect exceeds that of heat flux during the two increasing periods, whereas heat flux forcing has a slightly larger contribution during the 1980-96 cooling period.

We further examine the contributions of different processes to the trend pattern (Fig. 5). During 1965-79, strong warming occurred in the southeast IO near the exit of the ITF, and weaker warming spread over the equatorial and north IO. Afterward, PAC exerted 

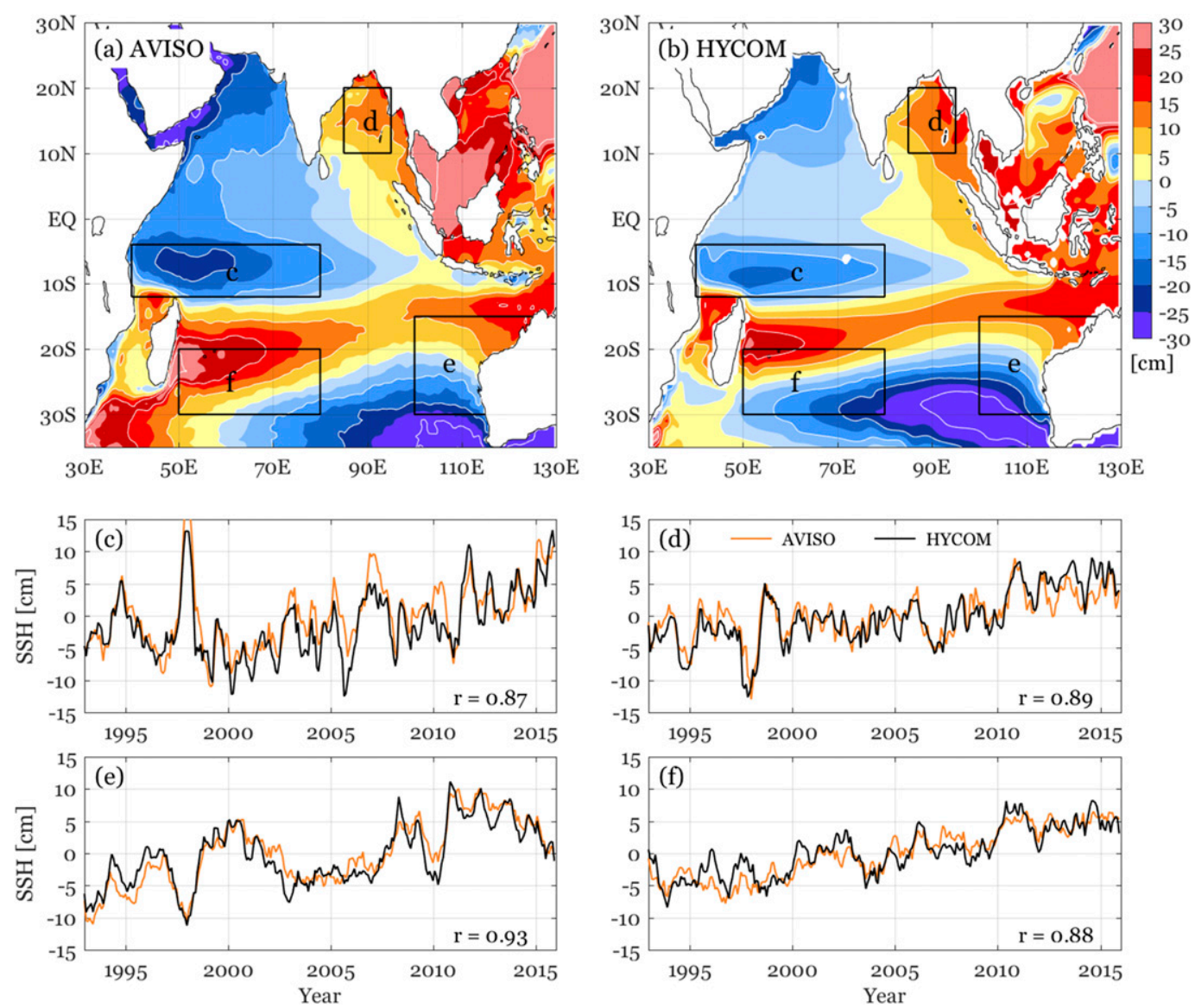

FIG. 3. Mean SSH of 1993-2015 derived from (a) AVISO satellite data and (b) HYCOM MR, with the IO Basin mean values removed. (c)-(f) Comparison of monthly SSH anomalies (with the climatological seasonal cycle removed) in the four regions defined in (a) and (b).

basinwide cooling and warming effects on the central and north IO during 1980-96 and 2000-14, respectively. All these trends were significant at $95 \%$ confidence level, whereas the subtropical south IO was exceptional. This region is largely affected by ocean internal variability and will be discussed later. Compared with the Pacific forcing, the IO local processes (MR - PAC) had a smaller contribution to the basin mean trend, partly because of the compensation between regional warming and cooling signals. However, local forcing induced strong warming over the western tropical IO and the southeast IO during 2000-14. Note that $T_{400}$ trends of MR - PAC during 2000-14 greatly resemble those of MR (Fig. 2f), confirming the dominant role of local processes during this period.

TAU includes both local wind-forcing effect within the IO and remote wind-forcing effect from the Pacific. Signatures of wind forcing include warming signals in the southwest tropical IO and southeast IO during 196579 , cooling of the central-to-eastern IO during 1980-96, and enhanced warming of the western-to-central tropical IO after 2000. Heat flux forcing (MR - TAU) primarily affected the subtropical south IO during the first two periods, whereas after 2000 , it induced enhanced warming throughout the IO Basin.

In almost all the HYCOM experiments, trends in the subtropical south IO tend to have large magnitudes but low statistical significance. These features conform to ocean internal variability. Existing research has pointed out the active mesoscale eddy variability in this region and its large impact on low-frequency ocean variations (e.g., Trenary and Han 2013; Li and Han 2015; Sérazin et al. 2016). This is proven by the results of the spinup run that used monthly climatologic forcing and therefore have no atmospheric forcing effect at interannual and lower frequencies (Fig. 6). The upper ocean has reached a quasi-steady state since the 10th year, and the standard deviation map of annual $T_{400}$ during the 11th30th years (Fig. 6a) clearly suggests the ocean internal origin for the large interannual-to-decadal variability in 

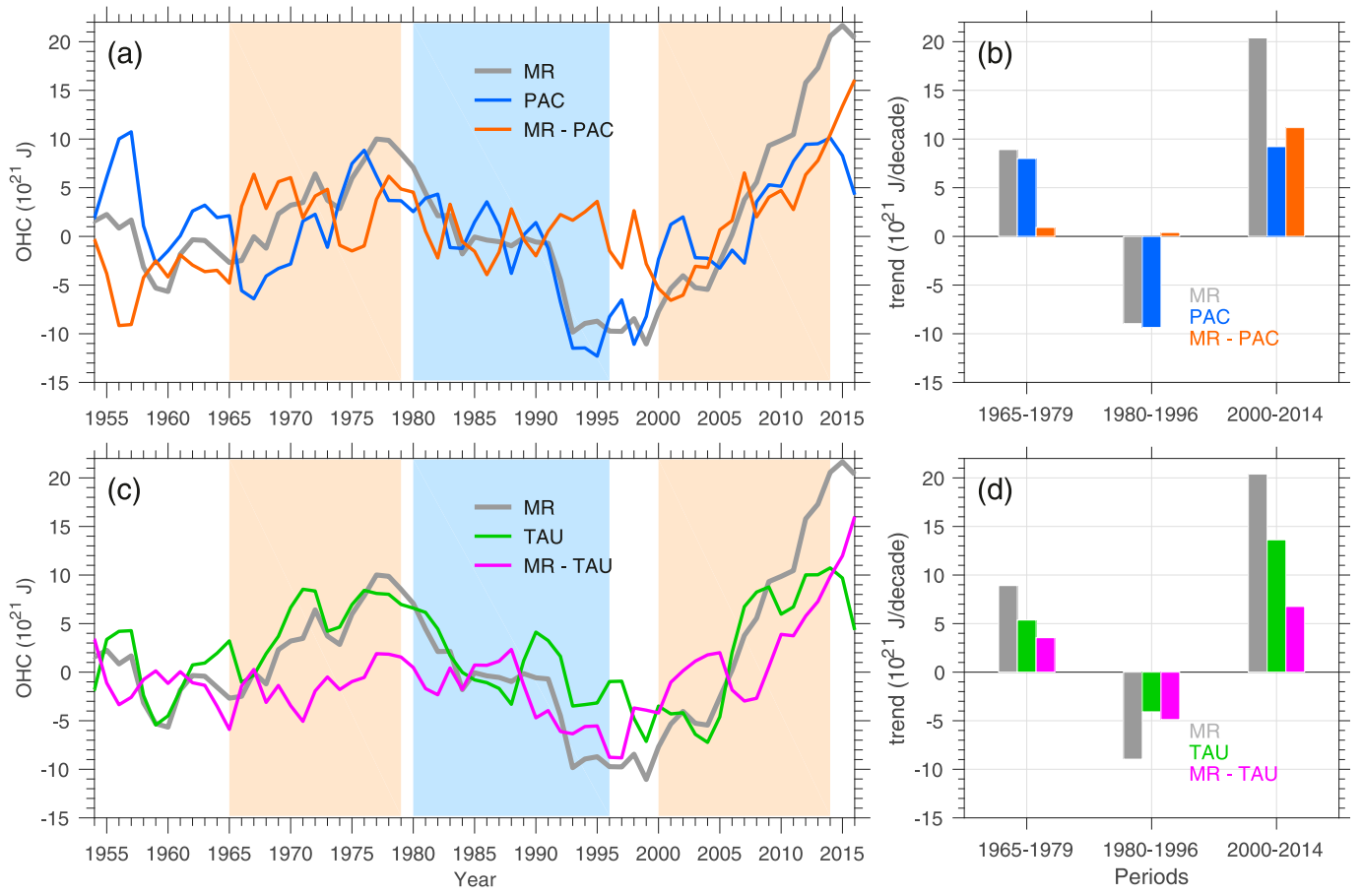

FIG. 4. (a) Annual Indian $\mathrm{OHC}_{400}$ and (b) its linear trends for 1965-79, 1980-96, and 2000-14, derived from MR and PAC experiments of HYCOM and their difference MR - PAC. (c),(d) As in (a),(b), but derived from MR, TAU, and MR - TAU.

the subtropical south IO. The decadal $T_{400}$ trend during the 21st-30th years shows strong signatures in the subtropical south IO (Fig. 6b), large enough to explain the trend signals in MR. These results raise caution for the interpretation of our HYCOM results, given that ocean internal variability is chaotic in nature and its phase cannot be reproduced by model simulation. In the subtropical south IO, MR showed strong warming trends during 1965-79 and 2000-14 and cooling trends in 1980-96, which were, however, not seen in PAC or TAU. It means that ocean internal variability happened to amplify the Indian $\mathrm{OHC}_{400}$ trends of $\mathrm{MR}$ in all three periods, and this could be a major cause for the overestimated $\mathrm{OHC}_{400}$ changes in MR relative to observation. It is, however, unknown how the ocean internal variability has affected the upper-IO variability in reality.

\section{b. Pacific wind forcing and ITF heat transport}

The above analysis broadly assesses the relative importance of different processes, and hereafter we further examine how each of them affects the upper IO, and their relationship with well-known climate phenomena such as the IPO and anthropogenic warming. First, we look at the Pacific forcing through the ocean channel (the ITF). Figure 7a compares ITF heat transport and temporal tendency of $\mathrm{OHC}_{400}\left(\partial \mathrm{OHC}_{400} / \partial t\right)$ in PAC. The two variables show good agreement, with a linear correlation of $r=0.71$, confirming the dominance of the ITF in the Indian $\mathrm{OHC}_{400}$ variability in PAC. Strong and weak ITF years (Fig. 7, red and blue dots) were identified with a 0.5 standard deviation criterion. There were more strong ITF years in the two warming periods and more weak ITF years in the $1980-96$ cooling period. To better understand the ITF variability, Fig. 7b further compares the ITF heat transport estimates based on MR, PAC, and TAU. It is found that the three are highly consistent, showing merely detailed differences. A similar situation is seen in volume transport and mean temperature of the ITF (Fig. S3). These results indicate that the ITF variability is primarily dictated by the $\mathrm{Pa}-$ cific wind forcing. The mean temperature of the ITF water also exhibited pronounced decadal variations. The ITF water was evidently warmer during the two warming periods and thus contributed to the heat transport changes of the ITF, as suggested by Lee et al. (2015).

The results of Fig. 7 point to the need to understand the Pacific wind variations. The mean zonal wind stress $\tau^{x}$ anomalies of the three periods are displayed in Fig. S4. The tropical Pacific was dominated by anomalous easterly winds (negative $\tau^{x}$ anomalies) in the two 

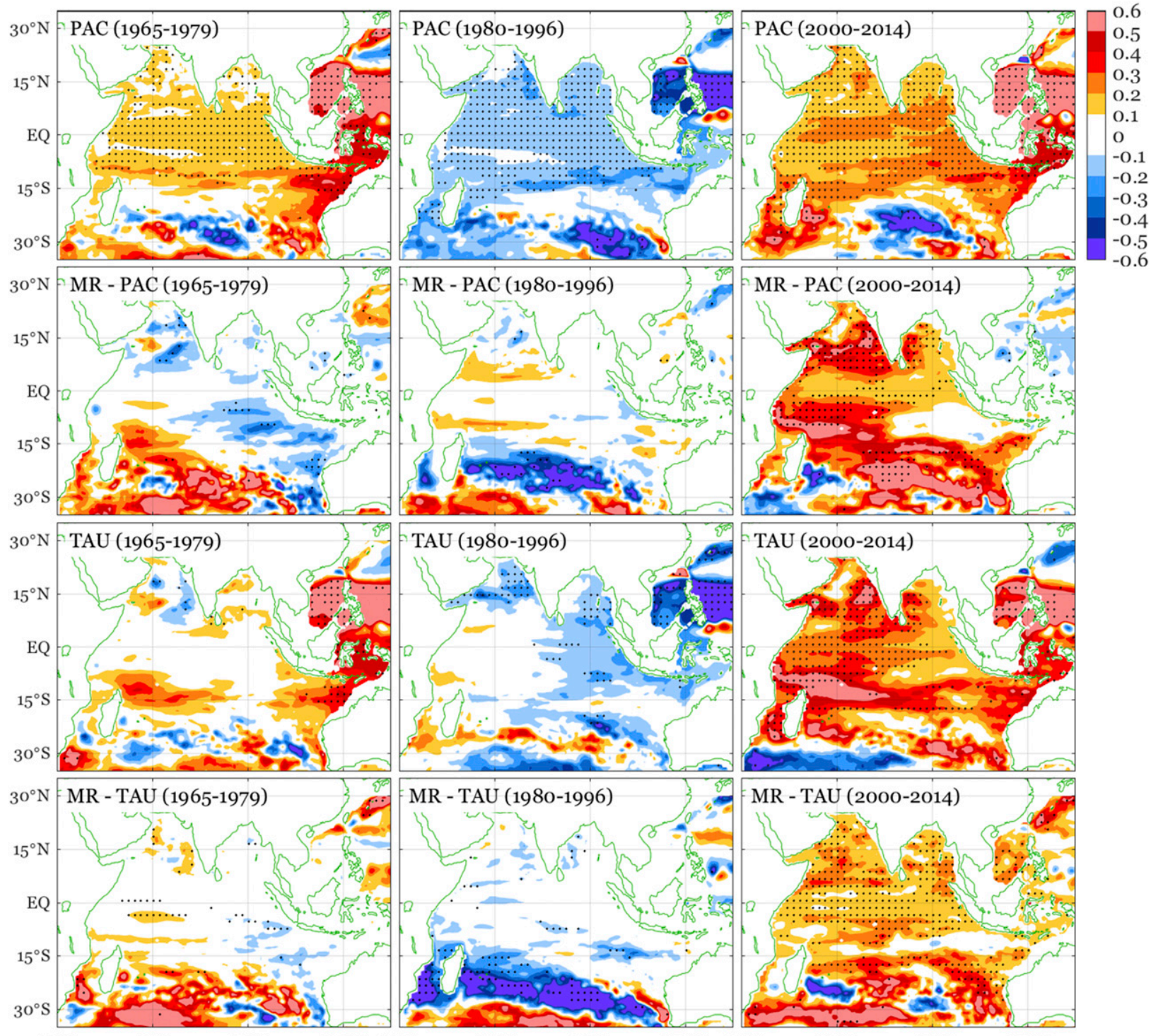

$30^{\circ} \mathrm{E}$

$60^{\circ} \mathrm{E}$

$90^{\circ} \mathrm{E}$

$120^{\circ} \mathrm{E} 30^{\circ} \mathrm{E}$

$60^{\circ} \mathrm{E}$

$90^{\circ} \mathrm{E}$

$120^{\circ} \mathrm{E} \quad 30^{\circ} \mathrm{E}$

$60^{\circ} \mathrm{E}$

$90^{\circ} \mathrm{E}$

$120^{\circ} \mathrm{E}$

FIG. 5. $T_{400}$ trends $\left(\mathrm{K}\right.$ decade $^{-1}$ ) during (left) 1965-79, (center) 1980-96, and (right) 2000-14 derived from PAC, MR - PAC, TAU, and MR - TAU. Stippling indicates exceeding $95 \%$ significance.

warming periods, indicative of a strengthening of the tropical trade winds, whereas during 1980-96 anomalous westerly winds suggested a weakening of the trade winds. These changes in Pacific trade winds were closely associated with the IPO (Fig. 7c). The correlation between the IPO index and the tropical Pacific-averaged $\tau^{x}$ is 0.86 . The two warming periods were generally under negative IPO conditions with more La Niña events and enhanced trade winds, while the 1980-96 period was characterized by a positive IPO condition with frequently occurring El Niños and weakened trade winds. The enhanced (weakened) Pacific trade winds during the negative (positive) IPO condition lead to strengthened (attenuated) ITF heat transport toward the IO during 1965-79 and 2000-14 (1980-96). The correlation between tropical Pacific $\tau^{x}$ and ITF heat transport is $r=-0.63$, also exceeding $95 \%$ significance.

Existing studies have demonstrated that the ITF variability mainly affects the south IO and has much weaker signatures in the north (Feng et al. 2004; Zhuang et al. 2013; Trenary and Han 2013; Dong and McPhaden 2016; $\mathrm{Li}$ et al. 2017). This is confirmed by composite maps of $\partial T_{400} / \partial t$ for the strong and weak ITF years (Figs. 8a,b). A stronger (weaker) ITF directly induces warming (cooling) of the south IO, with hotspots near the exit of the ITF and in the subtropical southeast IO. Moreover, 
(a) spin-up s.d. (11-30 years)

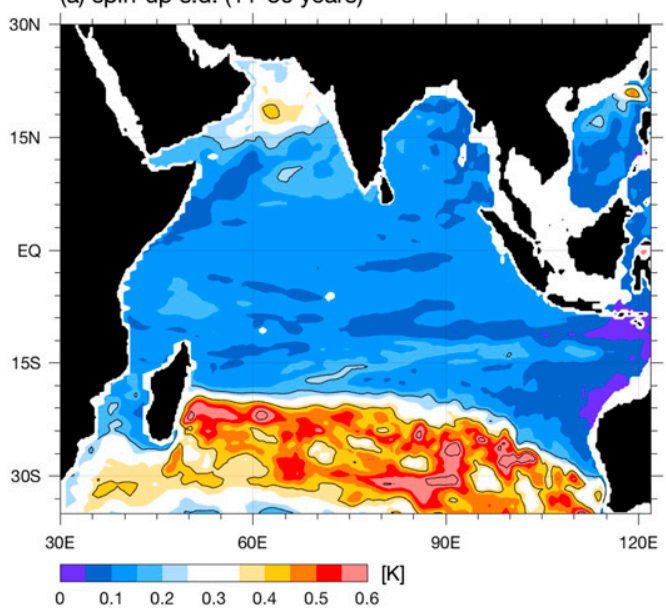

(b) spin-up trend (21-30 years)

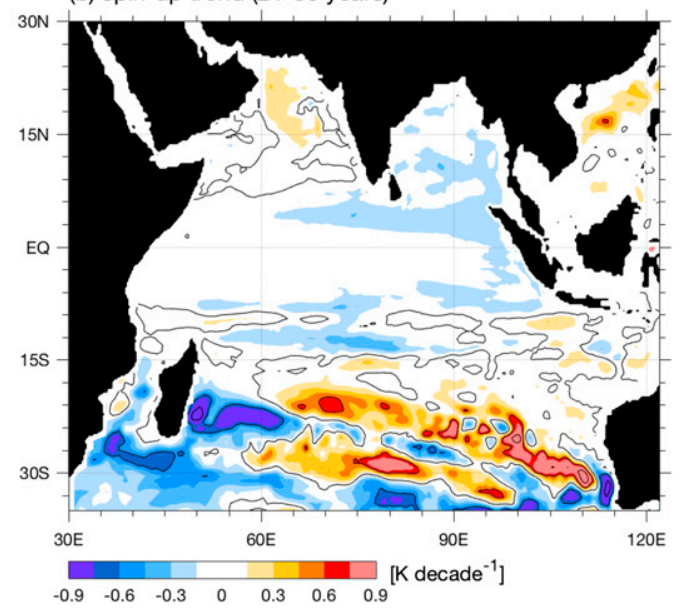

FIG. 6. (a) Standard deviation of annual $T_{400}$ from the 11 th to the 30 th year of the HYCOM spinup run. (b) Linear trend of annual $T_{400}$ from the 21st to the 30th year of HYCOM spinup run.

annual $\partial \mathrm{OHC}_{400} / \partial t$ of the south $\mathrm{IO}\left(\right.$ south of $5^{\circ} \mathrm{S}$ ) shows consistent variability with the ITF heat transport in PAC (Fig. 9a), showing a correlation of $r=0.73$. However, Fig. 5 shows that in PAC, the ITF is able to induce basinwide decadal warming/cooling over the north IO, although the trend signals are weaker than those in the south IO. The multidecadal warming/cooling and the corresponding sea level rise/fall in the north IO have been observed and reported by several recent studies but primarily attributed to local wind forcing, such as equatorial and monsoonal winds (Thompson et al. 2016; Srinivasu et al. 2017; Swapna et al. 2017). Therefore, a significant impact of the ITF over the north IO is quite new for our existing context of knowledge and requires careful examination.

For the first step, we answer the question as to how the ITF affects the north IO in PAC. Figure $9 \mathrm{~b}$ compares the $\partial \mathrm{OHC}_{400} / \partial t$ time series of the north and south IO in $\mathrm{PAC}$, divided by the $5^{\circ} \mathrm{S}$ latitude. A lagged relationship between them is clearly discerned. The two show low concurrent correlation $(r=-0.11$; insignificant at $95 \%$ confidence level) but high correlation when the south IO leads by two years $(r=0.86)$. This means that the north IO shows a lagged response to the ITF variability. The ITF is dynamically linked to the ocean circulation of the upper IO, particularly the shallow overturning circulation (Schott et al. 2002). Liu et al. (2016) showed that the IPO can modulate the cross-equatorial overturning cell (their Fig. 6b), which may cause anomalous upper-ocean heat exchanges between the south and north IO. To test this hypothesis, we compute the heat transport at $5^{\circ} \mathrm{S}$ over the IO Basin (Fig. 9c), which shows rather consistent variations with the north $\mathrm{IO} \partial \mathrm{OHC}_{400} / \partial t(r=0.56$; significant at $95 \%$ confidence level). This effect led to strong north IO warmings in 1976, 2001/02, and 2008-12, and coolings in 1966-68, 1984-93, and 2004/05. A further check over the $5^{\circ} \mathrm{S}$ section reveals that the heat transport mainly occurs in the western boundary region rather than in the interior (Fig. S5). The western boundary current at $5^{\circ} \mathrm{S}$, namely, the East African Coastal Current (Schott et al. 2009), is not significantly enhanced by the ITF. Instead, the water transported by the western boundary current is warmer, particularly in the thermocline (Fig. S5c). This effect leads to a basinwide cooling and warming signatures north of $5^{\circ} \mathrm{S}$, as shown by the composite $\partial T_{400} / \partial t$ for two years after the weak and strong ITF years, respectively (Figs. 8c,d). In the south IO, the tendencies that occurred two years later can partly offset those that occurred in strong and weak ITF years when computing the decadal trend. The 2-yr phase lag is short in comparison with the three periods considered here ( $>14$ years), and therefore basinwide north IO warming and cooling are seen in trend maps of PAC (Fig. 5). This also explains why the trend pattern of 2000-14 shows fundamental differences from the 200312 one revealed by Li et al. (2017) in which the southeast IO has much stronger warming than other areas. The 2000-14 period includes the lagged effects of the 19982000 and 2010/11 La Niña conditions that induce north IO warming and southeast IO cooling as in Fig. 8d.

A further question naturally arises as to whether the processes elucidated above are realistic or artificial. Here we are able to gain some insights by looking at MR results and observational data. Figure S6 demonstrates that in MR, despite local atmospheric forcing effects, the lagged correlation between the south and north IO still holds true $(r=0.67)$, and the heat transport at $5^{\circ} \mathrm{S}$ strongly affects the north IO $(r=0.41$; significant at $95 \%$ 

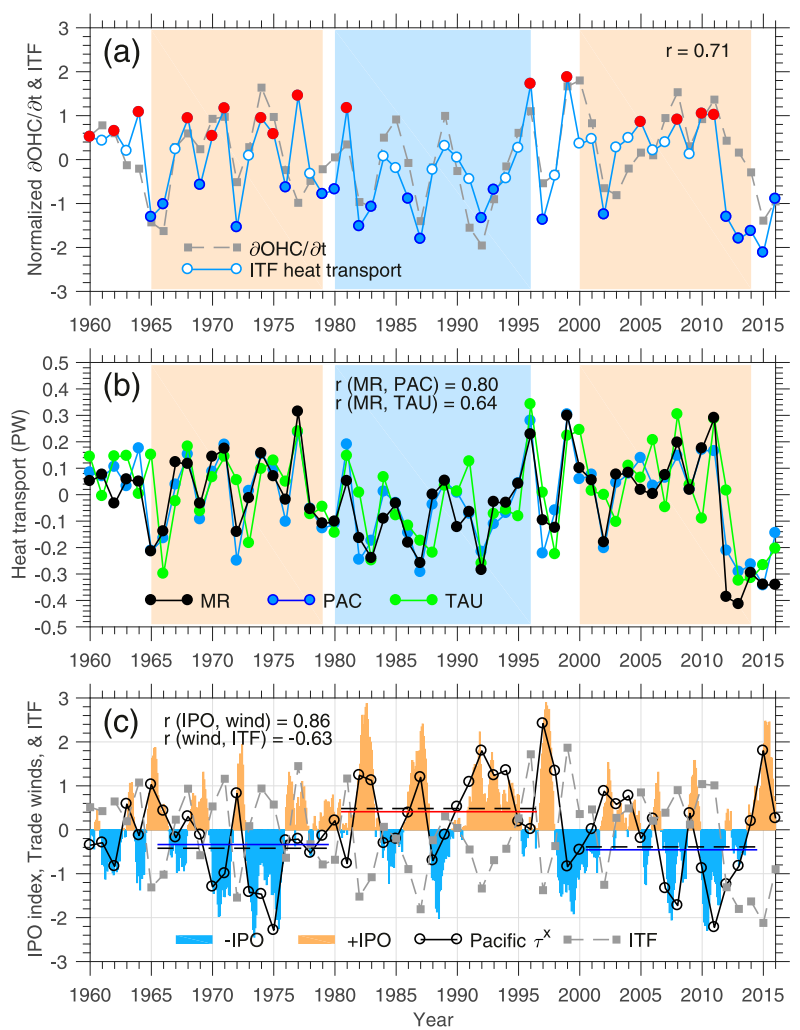

FIG. 7. (a) Normalized Indian $\mathrm{OHC}_{400}$ tendency $\left(\partial \mathrm{OHC}_{400} / \partial t\right)$ and the ITF heat transport in PAC. ITF heat transport values higher (lower) than the $+0.5(-0.5)$ standard deviation value are plotted as red (blue) dots, representing the strong (weak) ITF years. (b) Heat transport ( $1 \mathrm{PW}=10^{15} \mathrm{~W}$ ) of the ITF derived from MR, PAC, and TAU. (c) Normalized tropical Pacific $\tau^{x}\left(150^{\circ} \mathrm{E}-\right.$ $\left.120^{\circ} \mathrm{W}, 10^{\circ} \mathrm{S}-10^{\circ} \mathrm{N}\right)$, IPO index, and ITF heat transport. The mean values of $\tau^{x}$ (IPO index) for the three periods are plotted as dashed black (solid blue/red) straight lines. Here the ITF transport is computed at $5^{\circ} \mathrm{S}$ by integrating the meridional current over $106^{\circ}-$ $136^{\circ} \mathrm{E}$ and $0-400 \mathrm{~m}$, and southward transport (toward the IO) is defined positive. Each variable is shown as the anomaly relative to the 1980-2010 mean value.

confidence level). In the composite maps of MR, the overall warming/cooling of the north IO are also seen two years after the ITF extremes (Figs. S7a,b), although the spatial patterns are not quasi-uniform because of the modifications of local forcing. These results indicate that the ITF's effects on the north IO can be tested with observations. Figures S7c and S7d show the observed composite $\partial T_{400} / \partial t$ maps two years after the weak and strong ITF years, respectively, which are basically consistent with those of MR, albeit with prevailingly weaker magnitudes. Furthermore, the lagged correlation between the south and north IO also holds in observation (Fig. S8a), showing a correlation of $r=0.32$ when the south IO leads by two years (exceeding $95 \%$ significance, assuming each year has independent degree of freedom). The observed north $\mathrm{IO} \mathrm{OHC}_{400}$ agrees quite well with that in MR (Fig. S8b; $r=0.68$, significant at 99\%). Recalling Fig. 3d suggests that the HYCOMsimulated SSH in the Bay of Bengal is highly consistent with altimeter observation. If the ITF's large effect is an artifact of the model, these favorable comparisons with observation cannot be achieved. With these regards, the notable effect of the ITF on the north IO is likely realistic.

\section{c. Local wind forcing in the IO}

Given that the ITF heat transport variability is mainly controlled by the Pacific wind forcing, the difference between TAU and PAC (TAU - PAC) can approximately represent the effect of local wind stress forcing on the upper-IO heat content. Note that here the "local wind stress forcing" contains the atmospheric bridge effect from the Pacific. A weak cooling over the equatorial and north IO and a warming of the southwest tropical IO are seen during 1965-79 (Fig. 10a). The trend patterns were quite similar in the subsequent two periods (Figs. 10b,c), both showing widespread warming over the western tropical IO and weak cooling in the eastern equatorial IO and the eastern Bay of Bengal. During 2000-14, enhanced and significant warming trends were seen in the Arabian Sea and the southwest tropical IO. To better understand these trend structures, we also computed SSH trends (Figs. 10d-f) that show similar distributions to $T_{400}$ trends over the tropical IO in all three periods. The pattern correlations between $T_{400}$ and SSH trends are $0.69,0.64$, and 0.67 for the three periods. The consistency between SSH and $T_{400}$ indicates that the upper-ocean warming/cooling trends are a quasi-adiabatic ocean response to surface wind stress forcing, in the form of upper-ocean convergence/ divergence.

Equatorial zonal wind stress and off-equatorial Ekman pumping are both important in driving oceanic adjustments, and their trends are shown in Figs. $10 \mathrm{~g}-\mathrm{i}$. Here, Ekman pumping velocity $w_{E}=\operatorname{curl}(\tau / f) \rho_{0}^{-1}$, where $f$ is the Coriolis parameter and $\rho_{0}=1025 \mathrm{~kg} \mathrm{~m}^{-3}$ is the mean seawater density of the Ekman layer. During 1965-79, westerly and easterly wind trends were observed in the western and eastern equatorial basins, respectively. Together with the westerly wind trends in the south IO, these surface wind changes induced strong upwelling (positive $w_{E}$ trend) in the off-equatorial region in the central-to-eastern IO, which was the primary cause for the tropical IO cooling. In the subsequent two periods, easterly wind trends persisted near the equator, causing the eastern IO cooling through driving a shoaling thermocline (upwelling), and causing the western IO warming by deepening the thermocline, and therefore setting up the east-west temperature and SSH 
(a) weak ITF composite $($ lag $=0)$

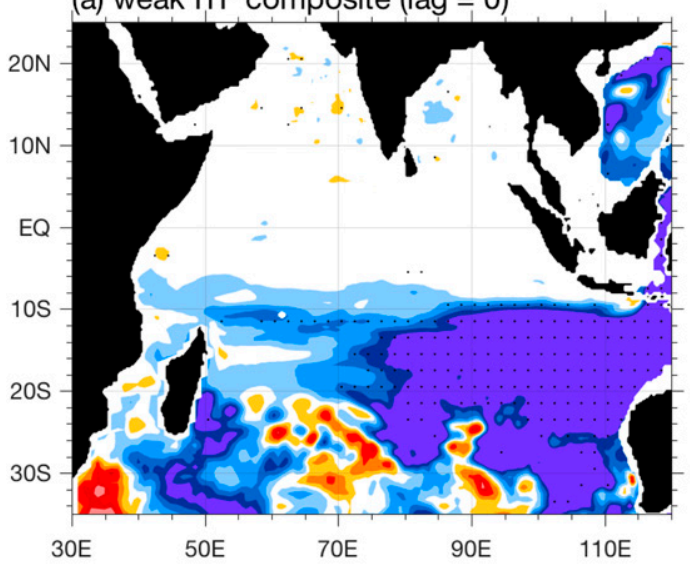

(c) weak ITF composite (lag $=2$ years)
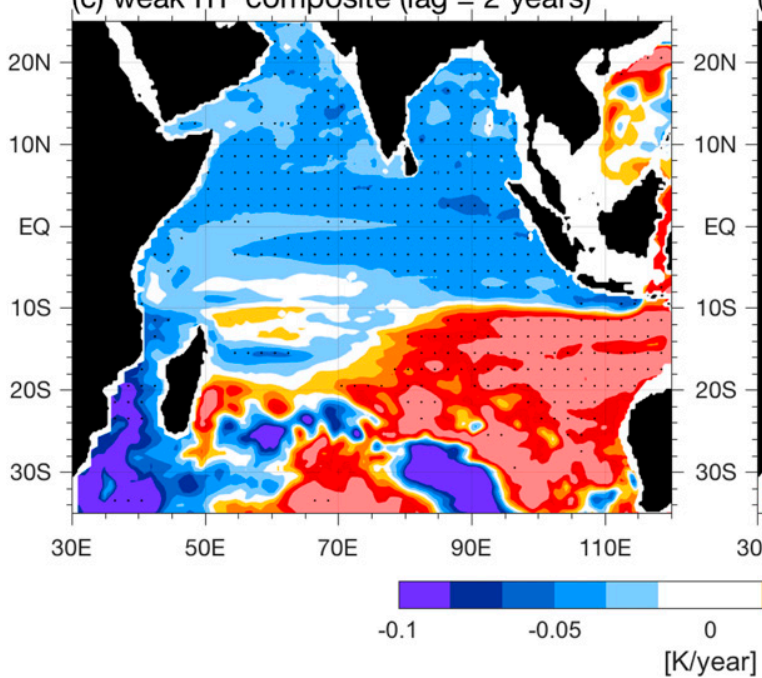

(b) strong ITF composite (lag $=0)$

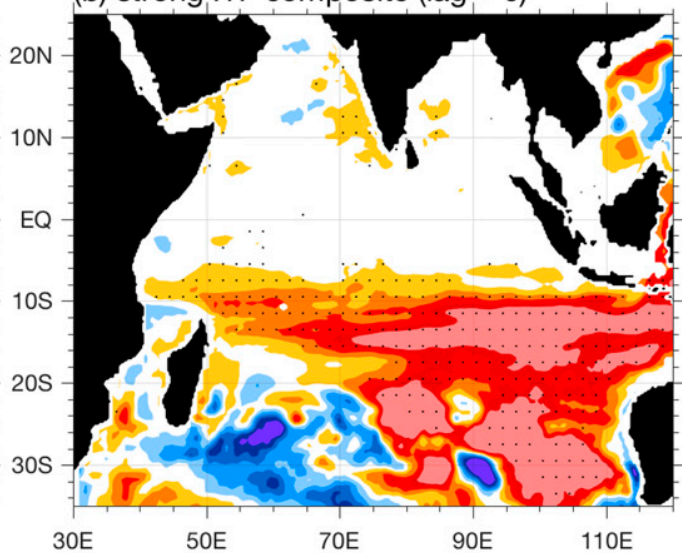

(d) strong ITF composite (lag $=2$ years)

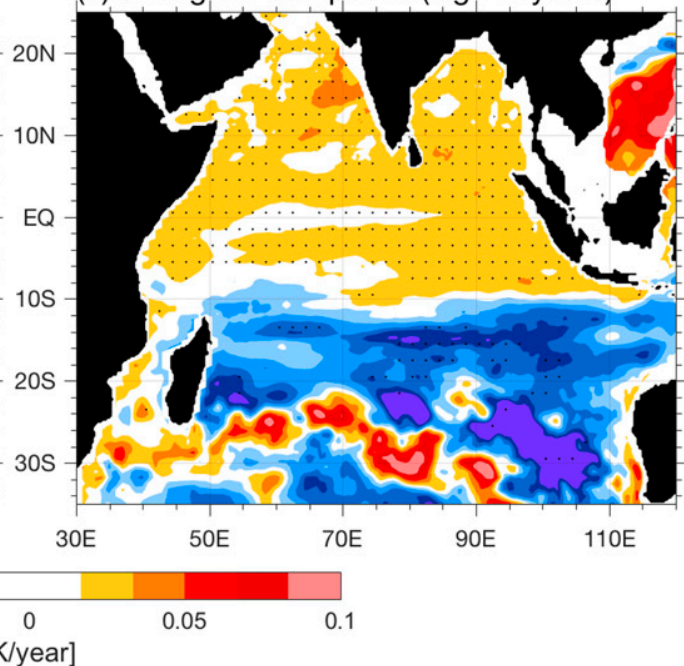

FIG. 8. (a),(b) Composite $\partial T_{400} / \partial t$ maps for the (a) weak and (b) strong ITF years derived from PAC. Weak and strong ITF years are shown in Fig. 7a. (c),(d) Composite $\partial T_{400} / \partial t$ for two years after the weak and strong years, also derived from PAC. Stippling indicates exceeding $95 \%$ significance.

gradients. On decadal time scale, the east-west $\mathrm{SSH}$ gradient is in quasi equilibrium with the zonal wind forcing (Han et al. 2017a), given that the decadal period is much longer than the equatorial adjustment time over the Indian Ocean, which is the time it takes for the equatorial Kelvin wave to cross the basin and the first meridional mode Rossby wave to return. It is approximately six months for the second baroclinic mode and even shorter for the first baroclinic mode (e.g., Han et al. 1999, 2011). The decadal period is also much longer than the adjustment time for the north IO, which is about 17 months (Shankar et al. 2010). This quasi-equilibrium balance between equatorial winds and zonal SSH gradient is set up by radiating transient equatorial Kelvin waves eastward [and subsequently poleward via coastal Kelvin waves to the Bay of Bengal and Sumatra-Java coasts, with part of their energy dissipated by mixing (e.g., Clarke and Liu 1994; Han and Webster 2002)] and westward-propagating Rossby waves. The easterly winds were also partly responsible for the western IO warming, through exciting downwelling Rossby waves. Propagation of equatorial waves and their close relationship with equatorial winds are shown in Fig. 11a.

The equatorial zonal winds were meridionally bounded by off-equatorial Ekman pumping. Positive (negative) $w_{E}$ trends drove westward-propagating upwelling (downwelling) Rossby waves in the tropical south IO and led to persistent SSH fall (rise) and upper-ocean cooling (warming) in the southwest tropical IO (Fig. 11b). Coastal winds were important in forming some regional trend structures through coastal downwelling/ upwelling. During 2000-14, the northeasterly winds 

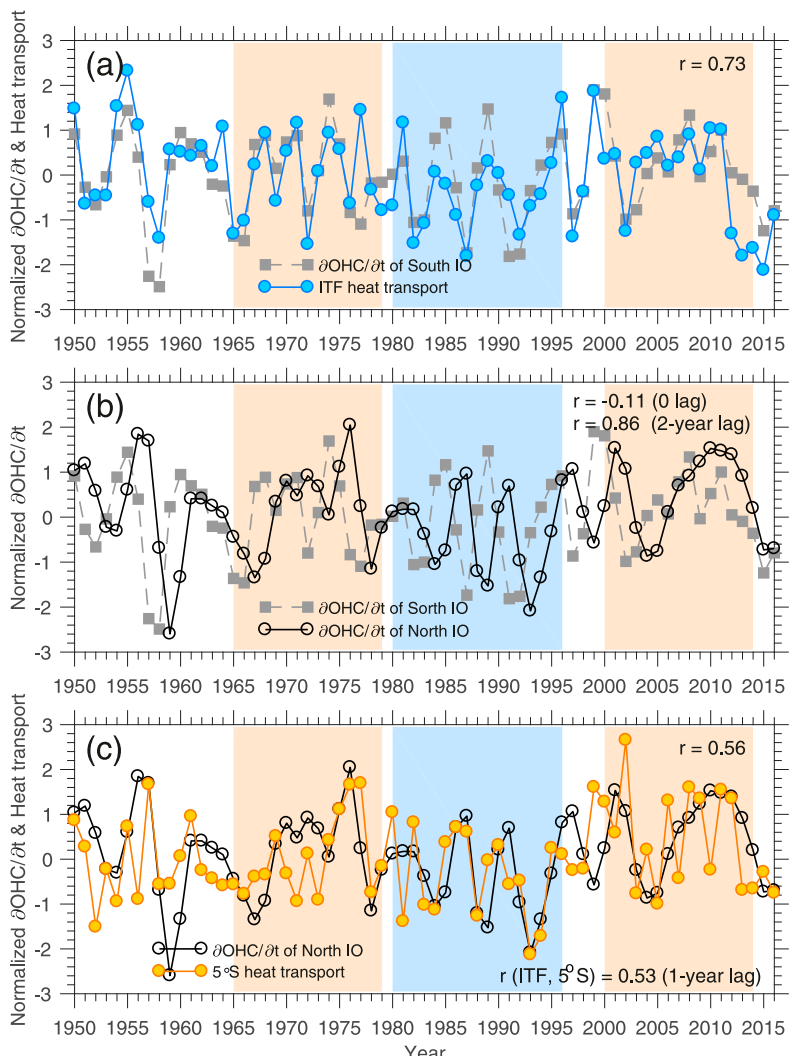

Year

FIG. 9. (a) Annual $\partial \mathrm{OHC}_{400} / \partial t$ of the south $\mathrm{IO}$ (south of $5^{\circ} \mathrm{S}$ ) and the ITF heat transport in PAC. (b) Annual $\partial \mathrm{OHC}_{400} / \partial t$ of the south $\mathrm{IO}$ and the north IO (north of $5^{\circ} \mathrm{S}$ ). (c) Annual $2 \mathrm{OHC}_{400} / \partial t$ of the north IO and meridional heat transport at $5^{\circ} \mathrm{S}$ (northward transport defined positive) in the IO for $0-400 \mathrm{~m}$. Each time series is normalized by its standard deviation.

along the west Asia-East Africa coast were favorable for the generation of local warming maximum in the western Arabian Sea, while in the southeast IO, the northerly winds induced strong warming along the West Australian coast (Li et al. 2017).

It is necessary to examine the relationship between the IO surface winds and the IPO. The composite for negative IPO years shows significant westerly anomalies in the equatorial region (Fig. S9a), as in the cases of 1965-79 and 2000-14 (Fig. S4). The IPO also induces westerly winds in the south IO, which were seen in 1965-79 (Fig. S4a) but not in 2000-14 (Fig. S4c). These zonal wind anomalies also induce strong $w_{E}$ anomalies in the off-equatorial tropics (Fig. S9b) that are critical for the redistribution of $\mathrm{OHC}_{400}$ changes.

We directly compare surface wind anomalies with the IPO index in three key regions (Fig. 12). Equatorial zonal winds and tropical south IO $w_{E}$ from ECMWF data show moderate correlations with IPO $(-0.40$ and -0.25 ). Most of IPO maxima (minima), indicating El Niño (La Niña) events, can cause equatorial easterly (westerly) winds and Ekman downwelling (upwelling) in the tropical south IO. These results are in line with existing understanding that ENSO and IPO have large atmospheric teleconnection imprints on the tropical IO (e.g., Klein et al. 1999; Alexander et al. 2002; Lee and McPhaden 2008; Han et al. 2017a). There are also variations not explained by IPO, probably arising from local variability in the IO such as the Indian Ocean dipole events independent of ENSO (Saji et al. 1999). In comparison, the alongshore winds in the southeast IO (along the West Australian coast) show larger uncertainties in the relationship with IPO $(r=0.08)$. Recent studies have pointed out a strong control of ENSO/ IPO in this region, with El Niño/positive IPO (La Niña/ negative IPO) driving anticyclonic (cyclonic) anomalous winds over the southeast IO, which involve southerly (northerly) winds along the West Australian coast (Tozuka et al. 2014; Feng et al. 2015; Li et al. 2017). This relationship is, in fact, approximately valid in some periods, particularly after 1990 . The low correlation might be attributed to the time-varying relationship between ENSO/IPO and the IO atmospheric circulation, or else to the large impact of atmospheric internal variability. NCEP-NCAR winds are highly consistent with ECMWF winds in the equatorial IO (Fig. 12a) but show large discrepancies in the south IO (Figs. 12b,c), particularly for the 1960s-70s when satellite data were unavailable for constraining the assimilation systems. Different wind products (ERA-Interim, ERA-20C, MERRA-2, NCEP-NCAR, and CFSR) show broadly consistent variations after 1979 (Fig. S10), confirming the relationships revealed above.

\section{d. Effects of surface heat fluxes}

In addition to wind forcing, surface heat flux is another important process causing $\mathrm{OHC}_{400}$ variability. In HYCOM simulations, surface SWR and LWR are taken from ECMWF data, while surface turbulent heat flux $Q_{T}$ is computed internally in the model with bulk formula. As referenced to OAFlux data, $Q_{T}$ in MR shows realistic spatial distribution and temporal variability over the Indian Ocean (Fig. S11). We first examine the heat flux forcing effect on the basin-integrated $\mathrm{OHC}_{400}$. The net surface heat flux $Q_{\text {net }}$ can well explain the Indian $\partial \mathrm{OHC}_{400} / \partial t$ in MR - TAU, showing a correlation of $r=$ 0.71 (Fig. 13a). The three components of $Q_{\text {net }}$, that is, SWR, LWR, and $Q_{T}$, played distinct roles in the three periods (Fig. 13b). The high $Q_{\text {net }}$ during 1965-75 was mainly induced by large SWR toward the ocean. In the subsequent two periods, SWR was greatly reduced, probably owing to the increasing anthropogenic aerosols over Asia (e.g., Cai et al. 2006, 2007); eruptions of 
(a) $T_{400}(1965-1979)$

(b) $\mathrm{T}_{400}(1980-1996)$

(c) $T_{400}(2000-2014)$
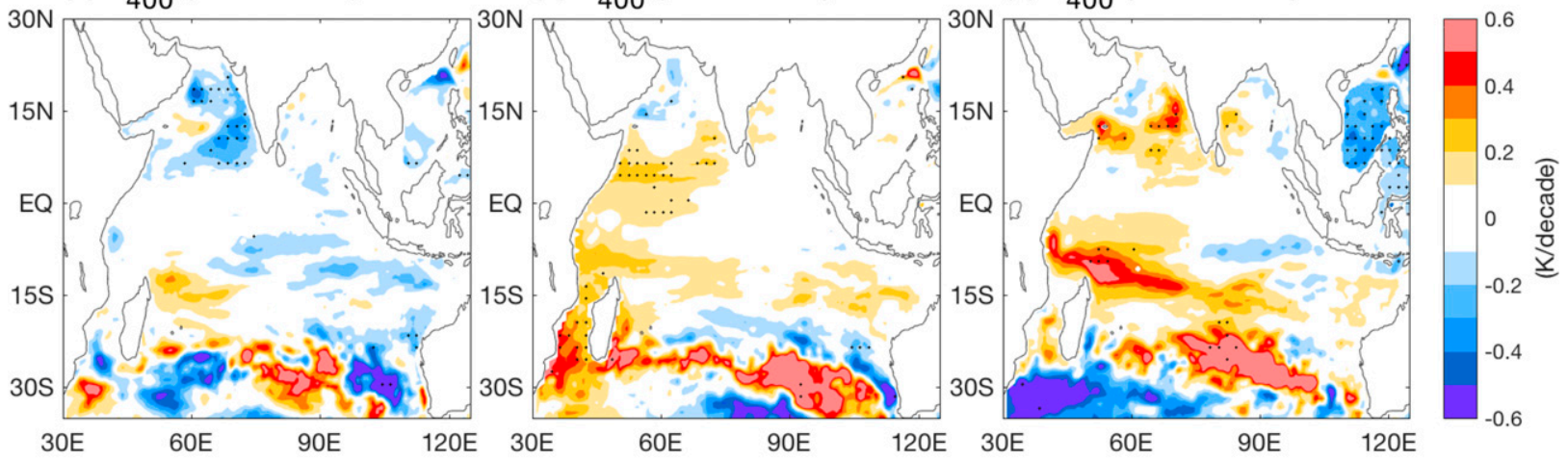

(d) SSH (1965-1979)

(e) SSH (1980-1996)
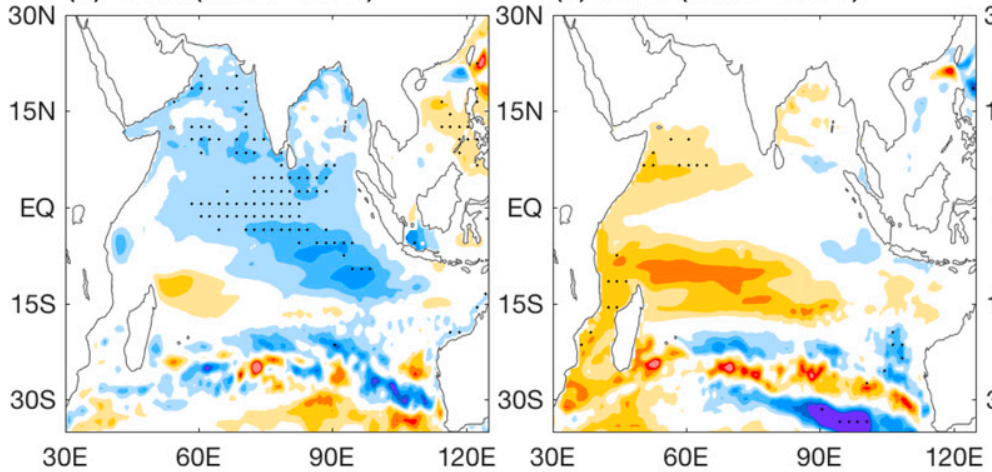

(f) SSH (2000-2014)

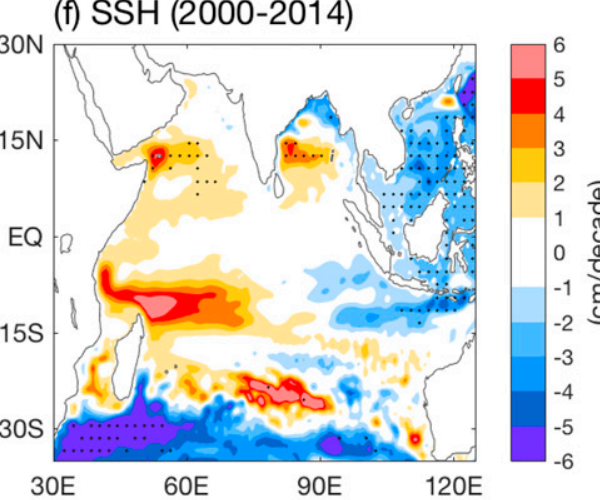

(g) Winds (1965-1979)

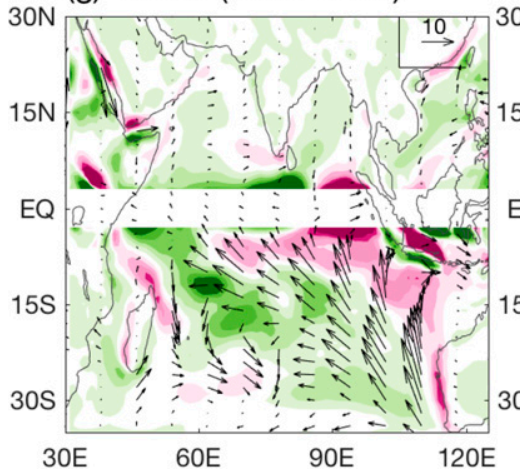

(h) Winds (1980-1996)

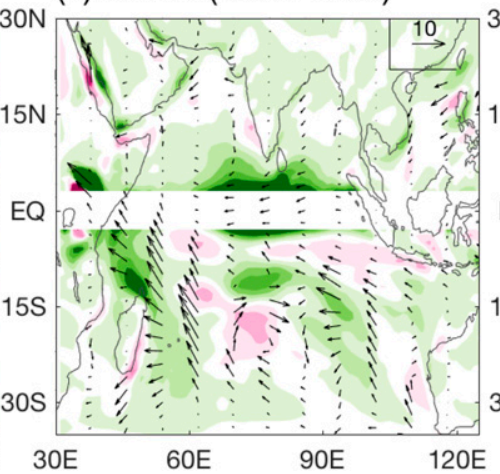

(i) Winds (2000-2014)

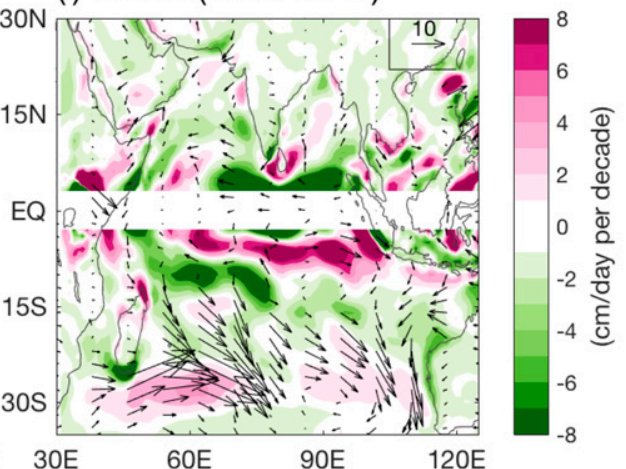

FIG. 10. $T_{400}$ trends during (a) 1965-79, (b) 1980-96, and (c) 2000-14, derived from TAU - PAC. (d)-(f) SSH trends derived from TAU -PAC. (g)-(i) Surface wind stress trends (black vectors; $10^{-4} \mathrm{~N} \mathrm{~m}^{-2}$ decade $^{-1}$ ) and Ekman pumping velocity $w_{E}$ trends (color shading; $\mathrm{cm}_{\text {day }}{ }^{-1}$ decade $^{-1}$ ) derived from ECMWF winds. Stippling in (a)-(g) indicates exceeding $95 \%$ significance.

El Chichón in 1982 and Mount Pinatubo in 1991 also contributed to the low SWR during 1980-96. In sharp contrast, because of the rise in greenhouse gas concentration, surface LWR exhibited a monotonic increase over the three periods and acted as the major driver of the enhanced warming during 2000-14. This is also consistent with the larger IO local forcing effect in this period. Although the effect of $Q_{T}$ was overall much weaker than SWR and LWR, it contributed to the cooling of 1980-96.
Surface heat fluxes are also important in determining the warming and cooling patterns. For example, the obvious and significant warming in the south IO during 1965-79 in observation and MR (Fig. 2) is seen in the MR - TAU solution (Fig. 5). Figure 13a confirms increased $Q_{\text {net }}$ in the south IO during this period. Checking the distributions of the three components suggests that this increased $Q_{\text {net }}$ arose primarily from SWR and secondarily from $Q_{T}$ (Fig. S12). The $Q_{\text {net }}$ had basinwide cooling and warming effects on the tropical 

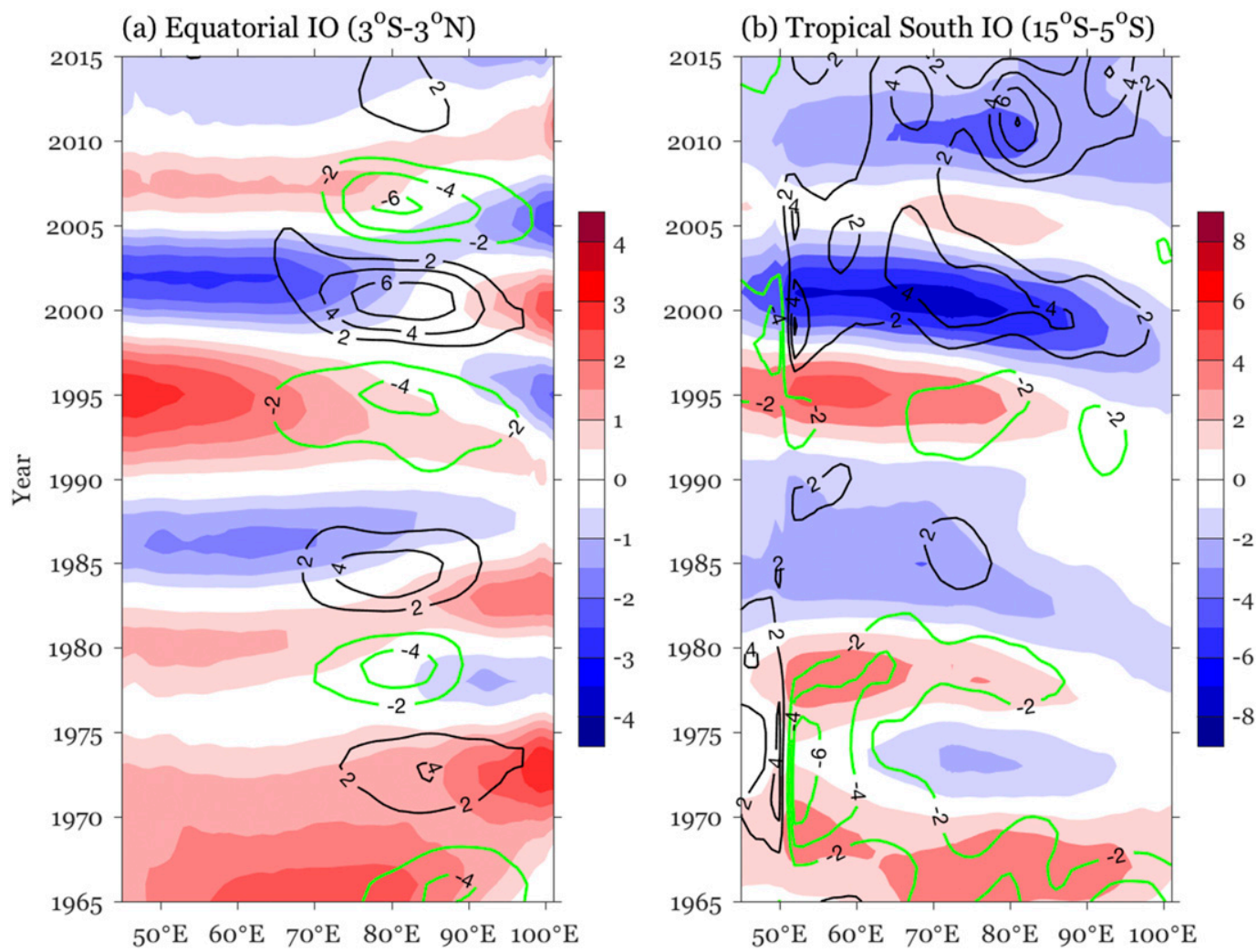

FIG. 11. (a) Time-longitude plot of 8-yr low-pass-filtered SSH anomaly ( $\mathrm{cm}$ ) derived from TAU - PAC in the equatorial IO $\left(3^{\circ} \mathrm{S}-3^{\circ} \mathrm{N}\right)$. Black (green) contours denote the positive (negative) 8-yr low-passed $\tau^{x}$ anomaly $\left(10^{-3}\right.$ $\mathrm{N} \mathrm{m}^{-2}$ ) derived from ECMWF winds. (b) As in (a), but in the tropical south IO $\left(15^{\circ}-5^{\circ} \mathrm{S}\right)$, and black (green) contours denote positive (negative) 8-yr low-passed $w_{E}\left(\mathrm{~cm} \mathrm{day}^{-1}\right)$

IO for 1980-96 and 2000-14, respectively, and LWR was the leading contributor; $Q_{T}$ also contributed to the enhanced warming of the tropical IO during 2000-14. A comparison with IPO composite maps (Fig. S13) indicates that $Q_{T}$ anomalies in the three periods contain evident signatures of the IPO, whereas SWR and LWR anomalies are not likely associated with the IPO.

\section{Summary and discussion}

In this study, we investigate characteristics and mechanisms of multidecadal changes of the upper-IO heat content through analyzing historical observational data and performing OGCM experiments. Four observational data products, namely, WOA, Ishii, EN4, and IAP, were employed to quantify the Indian $\mathrm{OHC}_{400}$ variability in the past half century. An Indo-Pacific basin simulation of HYCOM is able to faithfully reproduce the observed multidecadal $\mathrm{OHC}_{400}$ variability, and parallel experiments are performed to gain insights into the underlying mechanisms. The main findings are summarized as follows:
1) The four observational datasets, two ocean reanalysis products, and the HYCOM simulation reach consensus in showing the prominent multidecadal variations of the Indian $\mathrm{OHC}_{400}$, in spite of strong interannual fluctuations. The upper IO first experienced a heat content increase of $(5.9 \pm 2.5) \times$ $10^{21} \mathrm{~J} \mathrm{decade}^{-1}$ during $1965-79$, followed by a decrease of $(-5.2 \pm 2.5) \times 10^{21} \mathrm{~J} \mathrm{decade}^{-1}$ during 1980-96, and subsequently an enhanced increase of $(13.6 \pm 1.1) \times 10^{21} \mathrm{~J} \mathrm{decade}^{-1}$ from 2000 to 2014 .

2) Spatial structures of the upper-ocean temperature $\left(T_{400}\right)$ trends are different for the three periods. During 1965-79, strong warming mainly occurred in the southern subtropics; during 1980-96, quasiuniform cooling emerged over the entire IO Basin; and after 2000, the IO showed prevailing warming, with hotspots in the northwest IO and southern IO Basin.

3) By excluding interannual atmospheric forcing over the IO Basin, PAC assesses the Pacific forcing effect through the ITF. This effect was the leading driver for the 1965-79 $\mathrm{OHC}_{400}$ increase and subsequent 

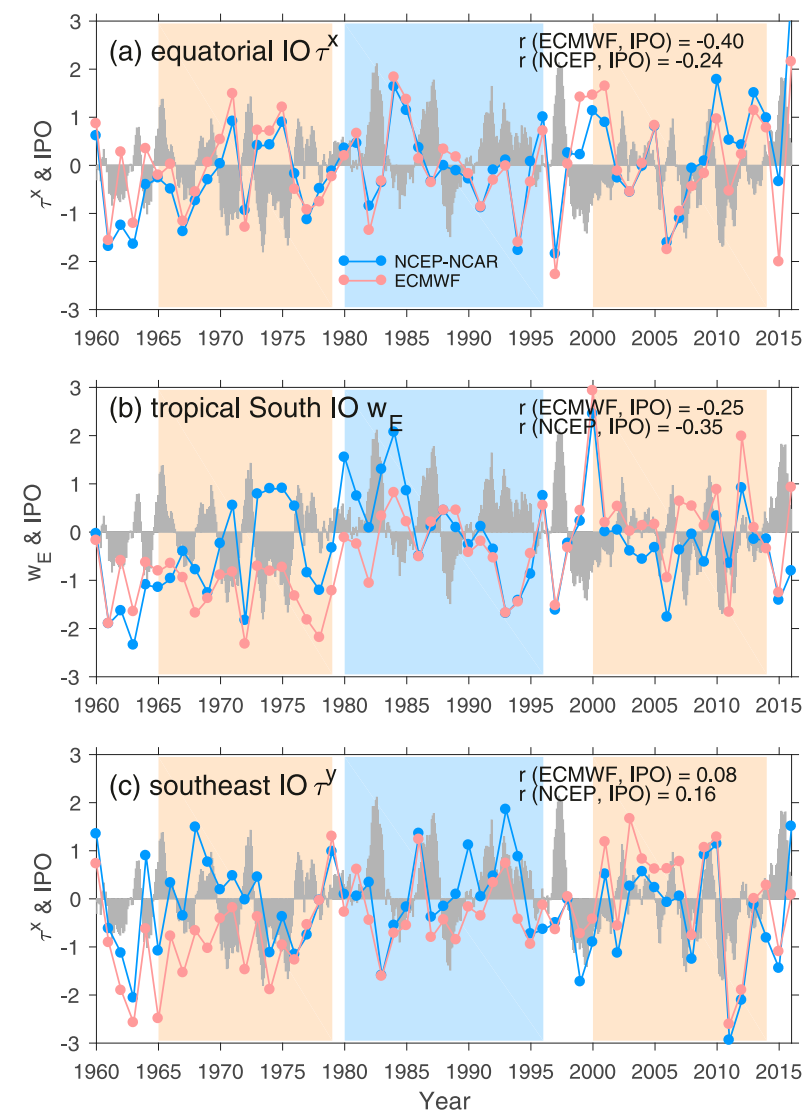

FIG. 12. (a) Zonal wind stress $\tau^{x}$ in the equatorial IO $\left(60^{\circ}-95^{\circ} \mathrm{E}\right.$, $5^{\circ} \mathrm{S}-5^{\circ} \mathrm{N}$ ), (b) Ekman pumping velocity $w_{E}$ in the tropical south IO $\left(50^{\circ}-90^{\circ} \mathrm{E}, 15^{\circ}-8^{\circ} \mathrm{S}\right)$, and (c) meridional wind stress $\tau^{y}$ along the West Australian coast $\left(110^{\circ}-120^{\circ} \mathrm{E}, 30^{\circ} \mathrm{S}-15^{\circ} \mathrm{N}\right)$, derived from ECMWF and NCEP-NCAR wind data. The IPO index is also plotted as gray bars.

1980-96 decrease, while for the post-2000 increase, local atmospheric forcing made a larger contribution. Variability of the ITF heat transport was primarily controlled by the tropical Pacific trade winds associated with the IPO. Strong and frequent El Niños (La Niñas) during the positive (negative) IPO condition exerted a strong cooling (warming) effect over the south IO through the ITF. These signatures of the ITF were able to affect the north IO through the meridional heat transport of the western boundary current, manifesting as a 2-yr lagged relationship between the south and north IO. Through this process, the ITF is able to induce basinwide north IO warming/cooling trends on multidecadal time scales.

4) Local wind forcing within the IO also had a significant impact on the upper-IO heat content through baroclinic waves. Local winds caused an overall cooling during 1965-79 and a warming during 198096, which attenuated the large $\mathrm{OHC}_{400}$ trends induced by Pacific wind forcing. This explains why the Pacific forcing effect (PAC) was much larger than the total wind stress effect (TAU) during the two periods (Figs. 4b,d). However, the IO winds were important for the post-2000 warming. Easterly wind trends near the equator, Ekman downwelling trends off the equator, northeasterly wind trends along the west Asia-East Africa coast, and northerly wind trends along the West Australian coast were all in favor of regional warming. Surface wind variations in the equatorial IO are likely robust and associated with the IPO, whereas those in the south IO are not significantly correlated with the IPO.

5) Surface heat flux forcing in the IO was also important. The high SWR during 1965-79 was a major driver of the upper-IO warming, while the lowered SWR during 1980-96, possibly due to aerosol effect and volcano eruptions, contributed to the upper-IO cooling. After 2000, the increased LWR, probably owing to anthropogenic greenhouse gas forcing, overwhelmed the cooling effect of SWR and greatly strengthened the rapid upper-IO warming. Although $Q_{T}$ has small contribution to the total $\mathrm{OHC}_{400}$ change of the IO, it plays a role in modifying the trend patterns and is closely associated with IPO.

The years 2015 and 2016 are not included in the last period because influence of the recent strong El Niño event should be discussed separately. In both observations and MR, the IO warming was suspended during 2015 and 2016 (Figs. 1 and 4), which is induced by the Pacific forcing (see the PAC results in Fig. 4a). In Fig. S14, we perform a particular analysis for the 2015/16 period. The Indian $\mathrm{OHC}_{400}$ decrease was $-1.3 \times$ $10^{21} \mathrm{~J} \mathrm{yr}^{-1}$, induced by El Niño through the decreased ITF heat transport (PAC run) and partly offset by local forcing (MR - PAC). The TAU run suggests that the joint effect of Pacific and IO winds together caused a strong cooling of $-5.3 \times 10^{21} \mathrm{~J} \mathrm{yr}^{-1}$ in the $\mathrm{IO}$, which overcame the heat flux-forced warming (MR - TAU). The $4.0 \times 10^{21} \mathrm{~J} \mathrm{yr}^{-1}$ warming is mainly contributed by LWR and secondarily by SWR. The high LWR probably reflects the increasing greenhouse gas concentration, while the high SWR is due to the suppressed convection (thus reduced cloudiness) over the IO during El Niño conditions.

Our analysis has also revealed uncertainties in surface wind and radiation forcing, which could be a major error source of our model simulation. The sensitivity of the modeled IO variability to different forcing datasets is not examined in the present study. Another issue affecting our results is the large effect of ocean internal variability on the subtropical south $\mathrm{IO}$, which might 


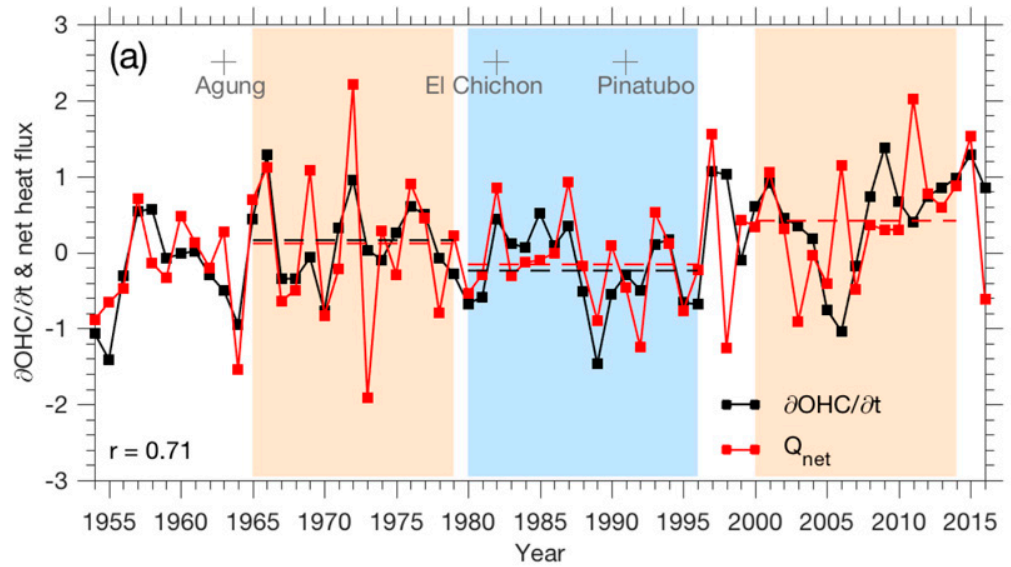

(c) $Q_{\text {net }}\left(W / m^{2}\right)$ of $1965-1979$

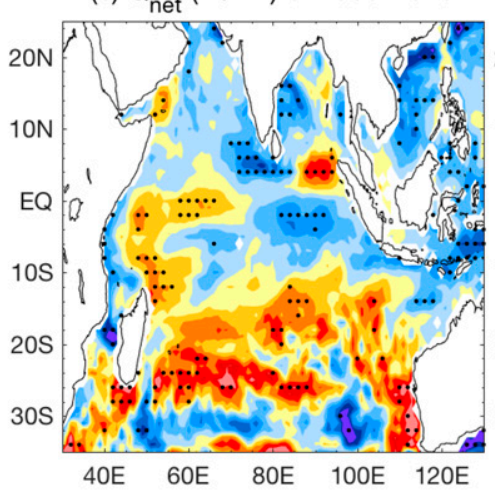

(d) $Q_{n e t}\left(W / m^{2}\right)$ of $1980-1996$

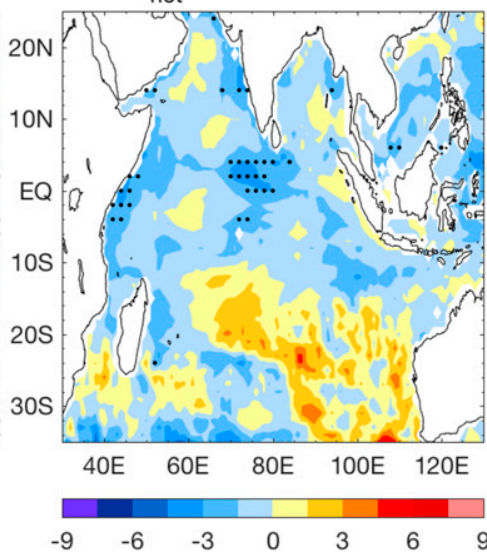

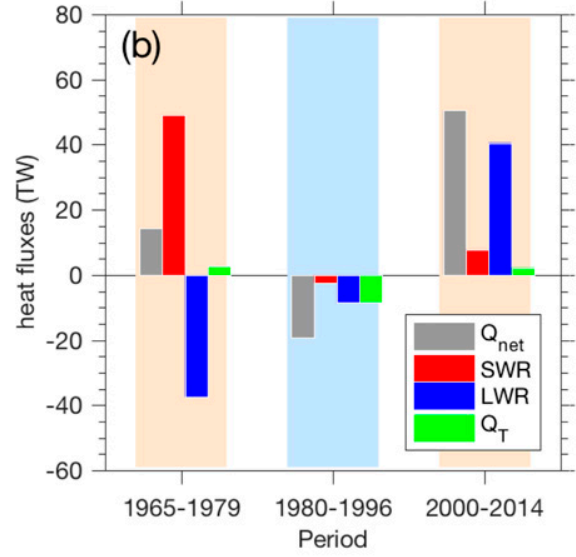

(e) $Q_{\text {net }}\left(W / m^{2}\right)$ of $2000-2014$

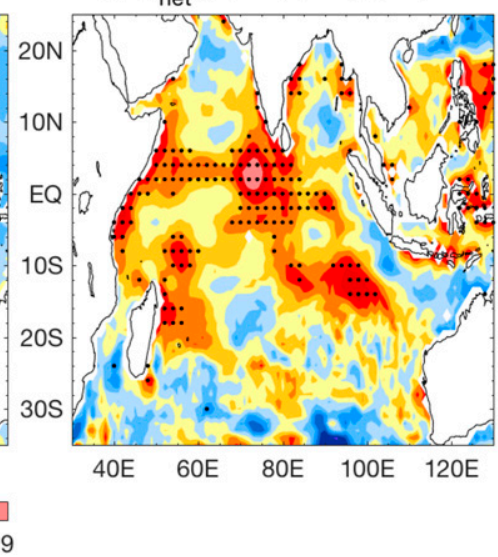

FIG. 13. (a) Normalized $\partial \mathrm{OHC}_{400} / \partial t$ and surface net heat flux $Q_{\text {net }}$ integrated over the IO, derived from MR - TAU; dashed lines denote their mean values for the three periods. (b) Anomalies of the IO-integrated $Q_{\text {net }}, \mathrm{SWR}, \mathrm{LWR}$, and turbulent heat flux $Q_{T}(1 \mathrm{TW}=$ $10^{12} \mathrm{~W}$ ) averaged over the three periods. SWR and LWR are based on merged ERA-20C and ERA-Interim data that are used to force HYCOM, while $Q_{\text {net }}$ and $Q_{T}$ are derived from MR - TAU. (c)-(e) Distributions of $Q_{\text {net }}$ anomaly for 1965-79, 1980-96, and 2000-14 derived from MR - TAU. Stippling indicates exceeding $95 \%$ significance.

be a primary cause for the overestimated Indian $\mathrm{OHC}_{400}$ variability in MR. It is still unknown how much the ocean internal variability has contributed to the $\mathrm{OHC}_{400}$ variabilities in our model simulation and in reality. This issue requires a carefully designed OGCM study to address, using eddy-resolving resolutions $\left(\sim 0.1^{\circ}\right.$ or higher) to more realistically represent the ocean internal variability (such as mesoscale eddies) and a multimember ensemble method (all members using the same atmospheric forcing but slightly different initial conditions) to isolate the "forced variability" and to estimate the ocean internal-origin variability amplitude. In addition to this effect, stochastic atmospheric forcing by ISOs and storm tracks, the Southern Ocean variability, and the Agulhas leakage are also not addressed here.

Existing studies showed that part of the warm water brought by the ITF can subsequently leave the Indian
Ocean through the Agulhas leakage (e.g., Gordon 1985; Biastoch et al. 2009; Beal et al. 2011). Yet the Agulhas leakage toward the Atlantic Ocean and the return flow to the Southern Ocean are not fully resolved in our IndoPacific simulation. Subsequently, most of the ITFinduced variability is trapped within the IO in our model instead of leaking to other regions, although part of the signals can be damped by the sponge layers on the open-ocean boundaries. This cannot only lead to the overestimation of the warming/cooling trends, but also cause an overrepresentation of the linkage between the north and south IO through meridional heat transport. Therefore, we have to stress caution when examining the ITF's effect on the north IO shown by our results, which might have been exaggerated because of our model setting. This effect should be confirmed with a global ocean model that can more realistically represent the interbasin ocean communications. 
In the present study, we put forward a time-varying mechanism for the upper-IO heat content variability, that is, local wind and heat flux forcing playing a more important role during the early twenty-first century than before. Recent studies have suggested that the relationship between the decadal tropical IO variability and the IPO has changed since the end of the twentieth century (Han et al. 2014, 2017a; Dong and McPhaden 2017; Zhang et al. 2018), possibly owing to the change of the climate background condition over the Indo-Pacific basin. It's also possible that the Atlantic Ocean warming during the past two decades may have exerted modulating effects over the Pacific and IO and altered their relationship on decadal time scales (McGregor et al. 2014; Li et al. 2016). The warming after 2000 was greatly amplified by surface LWR, which was not the case in the 1965-79 warming, implying a gradually enlarging effect of anthropogenic greenhouse gas warming ( $\mathrm{Li}$ et al. 2017). If the present emission level persists in the upcoming future, we envision a higher possibility for the occurrence of enhanced decadal warming of the IO. This will exert larger stress on local climate and the marine environment.

Acknowledgments. Three anonymous reviewers provide insightful comments for the early version of manuscript. This research is supported by National Natural Science Foundation of China (NSFC) Grant 41776001 and the National Program on Global Change and AirSea Interaction (Grant GASI-IPOVAI-01-01). W. Han is supported by NSF-AGS 1446480 and NSF-OCE 1658132. F. Wang is also supported by the AoShan Talents Program supported by Qingdao National Laboratory for Marine Science and Technology (Grant 2015ASTP). HYCOM simulations are performed on the Yellowstone supercomputer of NCAR CISL. WOA, Ishii, EN4, and IAP data are obtained from NOAA's NODC website (https://www.nodc.noaa.gov/OC5/indprod. html), JMA website (http://www.data.jma.go.jp), Met Office website (http://www.metoffice.gov.uk/hadobs/en4/), and Lijing Cheng's website (http://159.226.119.60/cheng/), respectively. AVISO satellite altimeter SSH data were downloaded from the AVISO website (http://www.aviso. oceanobs.com/). NCEP-NCAR, ERA-Interim/ERA-20C, and MERRA-2 data are available at NOAA's PSD website (https://www.esrl.noaa.gov/psd/), the ECMWF website (https://www.ecmwf.int/en/forecasts/datasets), and NASA's GSFC website (https://gmao.gsfc.nasa.gov/ reanalysis/MERRA-2/), and NCEP CFSR data are obtained from NOMADS (http://nomads.ncdc.noaa.gov/) and NCAR (http://rda.ucar.edu/pub/cfsr.html), respectively. Data analysis and graphing of this study were completed with a licensed Matlab 2017a program.

\section{REFERENCES}

Alexander, M. A., I. Bladé, M. Newman, J. R. Lanzante, N.-C. Lau, and J. D. Scott, 2002: The atmospheric bridge: The influence of ENSO teleconnections on air-sea interaction over the global oceans. J. Climate, 15, 2205-2231, https://doi.org/ 10.1175/1520-0442(2002)015<2205:TABTIO>2.0.CO;2.

Allan, R. J., J. Lindesay, and C. Reason, 1995: Multidecadal variability in the climate system over the Indian Ocean region during the austral summer. J. Climate, 8, 1853-1873, https://doi.org/ 10.1175/1520-0442(1995)008<1853:MVITCS > 2.0.CO;2.

Alory, G., S. Wijffels, and G. Meyers, 2007: Observed temperature trends in the Indian Ocean over 1960-1999 and associated mechanisms. Geophys. Res. Lett., 34, L02606, https://doi.org/ 10.1029/2006GL028044.

Beal, L. M., and Coauthors, 2011: On the role of the Agulhas system in ocean circulation and climate. Nature, 472, 429-436, https://doi.org/10.1038/nature09983.

Biastoch, A., C. W. Böning, F. U. Schwarzkopf, and J. R. E. Lutjeharms, 2009: Increase in Agulhas leakage due to poleward shift in the Southern Hemisphere westerlies. Nature, 462, 495-498, https://doi.org/10.1038/nature08519.

Bollasina, M. A., Y. Ming, and V. Ramaswamy, 2011: Anthropogenic aerosols and the weakening of the South Asian summer monsoon. Science, 334, 502-505, https://doi.org/10.1126/science.1204994.

Cai, W., G. Meyers, and G. Shi, 2005: Transmission of ENSO signal to the Indian Ocean. Geophys. Res. Lett., 32, L05616, https:// doi.org/10.1029/2004GL021736.

_ D. Bi, J. Church, T. Cowan, M. Dix, and L. Rotstayn, 2006: Panoceanic response to increasing anthropogenic aerosols: Impacts on the Southern Hemisphere oceanic circulation. Geophys. Res. Lett., 33, L21707, https://doi.org/10.1029/2006GL027513.

—, T. Cowan, M. Dix, L. Rotstayn, J. Ribbe, G. Shi, and S. Wijffels, 2007: Anthropogenic aerosol forcing and the structure of temperature trends in the southern Indian Ocean. Geophys. Res. Lett., 34, L14611, https://doi.org/10.1029/2007GL030380.

Carton, J. A., and B. S. Giese, 2008: A reanalysis of ocean climate using Simple Ocean Data Assimilation (SODA). Mon. Wea. Rev., 136, 2999-3017, https://doi.org/10.1175/2007MWR1978.1.

,$- \ldots$, and S. A. Grodsky, 2005: Sea level rise and the warming of the oceans in the Simple Ocean Data Assimilation (SODA) ocean reanalysis. J. Geophys. Res., 110, C09006, https://doi.org/ 10.1029/2004JC002817.

Chen, X., and K.-K. Tung, 2014: Varying planetary heat sink led to global-warming slowdown and acceleration. Science, 345, 897903, https://doi.org/10.1126/science.1254937.

Cheng, L., F. Zheng, and J. Zhu, 2015: Distinctive ocean interior changes during the recent warming slowdown. Sci. Rep., $\mathbf{5}$, 14346, https://doi.org/10.1038/srep14346.

— strumental biases and errors. Bull. Amer. Meteor. Soc., 97, 924-933, https://doi.org/10.1175/BAMS-D-15-00031.1.

, K. E. Trenberth, J. Fasullo, T. Boyer, J. Abraham, and J. Zhu, 2017: Improved estimates of ocean heat content from 1960 to 2015. Sci. Adv., 3, e1601545, https://doi.org/10.1126/ sciadv.1601545.

Clarke, A. J., and X. Liu, 1994: Interannual sea level in the northern and eastern Indian Ocean. J. Phys. Oceanogr., 24, 1224-1235, https://doi.org/10.1175/1520-0485(1994)024<1224: ISLITN $>2.0 . \mathrm{CO} ; 2$.

Compo, G. P., and Coauthors, 2011: The Twentieth Century Reanalysis project. Quart. J. Roy. Meteor. Soc., 137, 1-28, https:// doi.org/10.1002/qj.776. 
Dai, A., T. Qian, K. E. Trenberth, and J. D. Milliman, 2009: Changes in continental freshwater discharge from 1948 to 2004. J. Climate, 22, 2773-2792, https://doi.org/10.1175/ 2008JCLI2592.1.

Dee, D. P., and Coauthors, 2011: The ERA-Interim reanalysis: Configuration and performance of the data assimilation system. Quart. J. Roy. Meteor. Soc., 137, 553-597, https://doi.org/ 10.1002/qj.828.

Dong, L., and T. Zhou, 2014: The Indian Ocean sea surface temperature warming simulated by CMIP5 models during the twentieth century: Competing forcing roles of GHGs and anthropogenic aerosols. J. Climate, 27, 3348-3362, https:// doi.org/10.1175/JCLI-D-13-00396.1.

, and M. J. McPhaden, 2016: Interhemispheric SST gradient trends in the Indian Ocean prior to and during the recent global warming hiatus. J. Climate, 29, 9077-9095, https://doi.org/ 10.1175/JCLI-D-16-0130.1.

_, and __, 2017: Why has the relationship between Indian and Pacific Ocean decadal variability changed in recent decades? J. Climate, 30, 1971-1983, https://doi.org/10.1175/ JCLI-D-16-0313.1.

— T. Thou, and B. Wu, 2014: Indian Ocean warming during 1958-2004 simulated by a climate system model and its mechanism. Climate Dyn., 42, 203-217, https://doi.org/10.1007/ s00382-013-1722-z.

Du, Y., and S. P. Xie, 2008: Role of atmospheric adjustments in the TIO warming during the 20th century in climate models. Geophys. Res. Lett., 35, L08712, https://doi.org/10.1029/ 2008 GL033631.

Easterling, D. R., and M. F. Wehner, 2009: Is the climate warming or cooling? Geophys. Res. Lett., 36, L08706, https://doi.org/ 10.1029/2009GL037810.

England, M. H., and Coauthors, 2014: Recent intensification of wind-driven circulation in the Pacific and the ongoing warming hiatus. Nat. Climate Change, 4, 222-227, https://doi.org/ 10.1038/nclimate2106.

Fairall, C., E. F. Bradley, J. Hare, A. Grachev, and J. Edson, 2003: Bulk parameterization of air-sea fluxes: Updates and verification for the COARE algorithm. J. Climate, 16, 571-591, https://doi.org/10.1175/1520-0442(2003)016<0571: BPOASF $>2.0 . \mathrm{CO} ; 2$.

Feng, M., Y. Li, and G. Meyers, 2004: Multidecadal variations of Fremantle sea level: Footprint of climate variability in the tropical Pacific. Geophys. Res. Lett., 31, L16302, https://doi.org/ 10.1029/2004GL019947.

— M. J. McPhaden, S.-P. Xie, and J. Hafner, 2013: La Niña forces unprecedented Leeuwin Current warming in 2011. Sci. Rep., 3, 1277, https://doi.org/10.1038/srep01277.

—, H. H. Hendon, S.-P. Xie, A. G. Marshall, A. Schiller, Y. Kosaka, N. Caputi, and A. Pearce, 2015: Decadal increase in Ningaloo Niño since the late 1990s. Geophys. Res. Lett., 42, 104-112, https://doi.org/10.1002/2014gl062509.

Gleckler, P., T. Wigley, B. Santer, J. Gregory, K. AchutaRao, and K. Taylor, 2006: Volcanoes and climate: Krakatoa's signature persists in the ocean. Nature, 439, 675-675, https://doi.org/ 10.1038/439675a.

Good, S. A., M. J. Martin, and N. A. Rayner, 2013: EN4: Quality controlled ocean temperature and salinity profiles and monthly objective analyses with uncertainty estimates. J. Geophys. Res. Oceans, 118, 6704-6716, https://doi.org/10.1002/2013JC009067.

Gordon, A. L., 1985: Indian-Atlantic transfer of thermocline water at the Agulhas Retroflection. Science, 227, 1030-1033, https:// doi.org/10.1126/science.227.4690.1030.
Halliwell, G. R., 2004: Evaluation of vertical coordinate and vertical mixing algorithms in the HYbrid-Coordinate Ocean Model (HYCOM). Ocean Modell., 7, 285-322, https://doi.org/ 10.1016/j.ocemod.2003.10.002.

Han, W., and P. J. Webster, 2002: Forcing mechanisms of sea level interannual variability in the Bay of Bengal. J. Phys. Oceanogr., 32, 216-239, https://doi.org/10.1175/1520-0485(2002)032<0216: FMOSLI $>2.0 . \mathrm{CO} ; 2$.

— J. P. McCreary Jr., D. Anderson, and A. J. Mariano, 1999: Dynamics of the eastern surface jets in the equatorial Indian Ocean. J. Phys. Oceanogr., 29, 2191-2209, https://doi.org/ 10.1175/1520-0485(1999)029<2191:DOTESJ > 2.0.CO;2.

_ G. A. Meehl, and A. Hu, 2006: Interpretation of tropical thermocline cooling in the Indian and Pacific Oceans during recent decades. Geophys. Res. Lett., 33, L23615, https:// doi.org/10.1029/2006GL027982.

— change in a warming climate. Nat. Geosci., 3, 546-550, https:// doi.org/10.1038/ngeo901.

_ J. P. McCreary Jr., Y. Masumoto, J. Vialard, and B. Duncan, 2011: Basin resonances in the equatorial Indian Ocean. J. Phys. Oceanogr., 41, 1252-1270, https://doi.org/10.1175/ 2011JPO4591.1.

_ J. Vialard, M. J. McPhaden, T. Lee, Y. Masumoto, M. Feng, W. P. M. de Ruijter, 2014: Indian Ocean decadal variability: A review. Bull. Amer. Meteor. Soc., 95, 1679-1703, https:// doi.org/10.1175/BAMS-D-13-00028.1.

, G. A. Meehl, A. Hu, J. Zheng, J. Kenigson, J. Vialard, B. Rajagopalan, and Yanto, 2017a: Decadal variability of Indian and Pacific Walker cells since the 1960s: Do they covary on decadal time scales? J. Climate, 30, 8447-8468, https:// doi.org/10.1175/JCLI-D-16-0783.1.

— — - D. Stammer, A. Hu, B. Hamlington, J. Kenigson, H. Palanisamy, and P. Thompson, 2017b: Spatial patterns of sea level variability associated with natural internal climate modes. Surv. Geophys., 38, 217-250, https://doi.org/10.1007/ s10712-016-9386-y.

Henley, B., J. Gergis, D. Karoly, S. Power, J. Kennedy, and C. Folland, 2015: A tripole index for the interdecadal Pacific oscillation. Climate Dyn., 45, 3077-3090, https://doi.org/ 10.1007/s00382-015-2525-1.

Ishii, M., A. Shouji, S. Sugimoto, and T. Matsumoto, 2005: Objective analyses of sea-surface temperature and marine meteorological variables for the 20th century using ICOADS and the Kobe Collection. Int. J. Climatol., 25, 865-879, https:// doi.org/10.1002/joc.1169.

Kalnay, E., and Coauthors, 1996: The NCEP/NCAR 40-Year Reanalysis Project. Bull. Amer. Meteor. Soc., 77, 437-471, https:// doi.org/10.1175/1520-0477(1996)077<0437:TNYRP>2.0.CO;2.

Kara, A. B., H. E. Hurlburt, and A. J. Wallcraft, 2005: Stabilitydependent exchange coefficients for air-sea fluxes. J. Atmos. Oceanic Technol., 22, 1080-1094, https://doi.org/10.1175/ JTECH1747.1.

Klein, S. A., B. J. Soden, and N. C. Lau, 1999: Remote sea surface temperature variations during ENSO: Evidence for a tropical atmospheric bridge. J. Climate, 12, 917-932, https://doi.org/ 10.1175/1520-0442(1999)012<0917:RSSTVD>2.0.CO;2.

Kosaka, Y., and S.-P. Xie, 2013: Recent global-warming hiatus tied to equatorial Pacific surface cooling. Nature, 501, 403-407, https://doi.org/10.1038/nature12534.

_ and - 2016: The tropical Pacific as a key pacemaker of the variable rates of global warming. Nat. Geosci., 9, 669-673, https://doi.org/10.1038/ngeo2770. 
Lee, S.-K., W. Park, M. O. Baringer, A. L. Gordon, B. Huber, and Y. Liu, 2015: Pacific origin of the abrupt increase in Indian Ocean heat content during the warming hiatus. Nat. Geosci., 8 , 445-449, https://doi.org/10.1038/ngeo2438.

Lee, T., 2004: Decadal weakening of the shallow overturning circulation in the south Indian Ocean. Geophys. Res. Lett., 31, L18305, https://doi.org/10.1029/2004GL020884; Corrigendum, 31, L22302, https://doi.org/10.1029/2004GL021774.

— , and M. J. McPhaden, 2008: Decadal phase change in largescale sea level and winds in the Indo-Pacific region at the end of the 20th century. Geophys. Res. Lett., 35, L01605, https:// doi.org/10.1029/2007GL032419.

Le Traon, P. Y., F. Nadal, and N. Ducet, 1998: An improved mapping method of multisatellite altimeter data. J. Atmos. Oceanic Technol., 15, 522-534, https://doi.org/10.1175/ 1520-0426(1998)015<0522:AIMMOM>2.0.CO;2.

Levitus, S., J. I. Antonov, T. P. Boyer, R. A. Locarnini, H. E. Garcia, and A. V. Mishonov, 2009: Global ocean heat content 1955-2008 in light of recently revealed instrumentation problems. Geophys. Res. Lett., 36, L07608, https://oi.org/ 10.1029/2008GL037155.

Li, X., S.-P. Xie, S. T. Gille, and C. Yoo, 2016: Atlantic-induced pantropical climate change over the past three decades. Nat. Climate Change, 6, 275-279, https://doi.org/10.1038/nclimate2840.

Li, Y., and W. Han, 2015: Decadal sea level variations in the Indian Ocean investigated with HYCOM: Roles of climate modes, ocean internal variability, and stochastic wind forcing. J. Climate, 28, 9143-9165, https://doi.org/10.1175/JCLI-D-15-0252.1.

— , and F. Wang, 2015: Thermocline spiciness variations in the tropical Indian Ocean observed during 2003-2014. Deep-Sea Res. I, 97, 52-66, https://doi.org/10.1016/j.dsr.2014.12.004.

_- W. Han, and L. Zhang, 2017: Enhanced decadal warming of the southeast Indian Ocean during the recent global surface warming slowdown. Geophys. Res. Lett., 44, 9876-9884, https://doi.org/10.1002/2017GL075050.

Liang, X., and L. Yu, 2016: Variations of the global net air-sea heat flux during the "hiatus" period (2001-10). J. Climate, 29, 36473660, https://doi.org/10.1175/JCLI-D-15-0626.1.

Liu, W., S.-P. Xie, and J. Lu, 2016: Tracking ocean heat uptake during the surface warming hiatus. Nat. Commun., 7, 10926, https://doi.org/10.1038/ncomms10926.

Llovel, W., and T. Lee, 2015: Importance and origin of halosteric contribution to sea level change in the southeast Indian Ocean during 2005-2013. Geophys. Res. Lett., 42, 1148-1157, https:// doi.org/10.1002/2014GL062611.

Locarnini, R. A., and Coauthors, 2013: Temperature. Vol. 1, World Ocean Atlas 2013, NOAA Atlas NESDIS 73, 40 pp., http:// data.nodc.noaa.gov/woa/WOA13/DOC/woa13_vol1.pdf.

McGregor, S., A. Timmermann, M. F. Stuecker, M. H. England, M. Merrifield, F.-F. Jin, and Y. Chikamoto, 2014: Recent Walker circulation strengthening and Pacific cooling amplified by Atlantic warming. Nat. Climate Change, 4, 888-892, https:// doi.org/10.1038/nclimate2330.

Meehl, G. A., J. M. Arblaster, J. T. Fasullo, A. Hu, and K. E. Trenberth, 2011: Model-based evidence of deep-ocean heat uptake during surface-temperature hiatus periods. Nat. Climate Change, 1, 360-364, https://doi.org/10.1038/nclimate1229.

-, H. Teng, and J. M. Arblaster, 2014: Climate model simulations of the observed early-2000s hiatus of global warming. Nat. Climate Change, 4, 898-902, https://doi.org/10.1038/ nclimate2357.

— A. Hu, B. D. Santer, and S.-P. Xie, 2016: Contribution of the interdecadal Pacific oscillation to twentieth-century global surface temperature trends. Nat. Climate Change, 6, 10051008, https://doi.org/10.1038/nclimate3107.

Meyers, G., 1996: Variation of Indonesian Throughflow and the El Niño-Southern Oscillation. J. Geophys. Res., 101, 12255 12 263, https://doi.org/10.1029/95JC03729.

Nicholls, R. J., and A. Cazenave, 2010: Sea-level rise and its impact on coastal zones. Science, 328, 1517-1520, https://doi.org/ 10.1126/science. 1185782 .

Nidheesh, A. G., M. Lengaigne, J. Vialard, A. S. Unnikrishnan, and H. Dayan, 2013: Decadal and long-term sea level variability in the tropical Indo-Pacific Ocean. Climate Dyn., 41, 381-402, https://doi.org/10.1007/s00382-012-1463-4.

Nieves, V., J. K. Willis, and W. C. Patzert, 2015: Recent hiatus caused by decadal shift in Indo-Pacific heating. Science, 349, 532-535, https://doi.org/10.1126/science.aaa4521.

Poli, P., and Coauthors, 2016: ERA-20C: An atmospheric reanalysis of the twentieth century. J. Climate, 29, 4083-4097, https://doi.org/10.1175/JCLI-D-15-0556.1.

Power, S., T. Casey, C. Folland, A. Colman, and V. Mehta, 1999: Inter-decadal modulation of the impact of ENSO on Australia. Climate Dyn., 15, 319-324, https://doi.org/10.1007/s003820050284.

Rayner, N. A., D. E. Parker, E. B. Horton, C. K. Folland, L. V. Alexander, D. P. Rowell, E. C. Kent, and A. Kaplan, 2003: Global analyses of sea surface temperature, sea ice, and night marine air temperature since the late nineteenth century. J. Geophys. Res., 108, 4407, https://doi.org/10.1029/2002JD002670.

Rienecker, M. M., and Coauthors, 2011: MERRA: NASA's Modern-Era Retrospective Analysis for Research and Applications. J. Climate, 24, 3624-3648, https://doi.org/10.1175/ JCLI-D-11-00015.1.

Roemmich, D., J. Church, J. Gilson, D. Monselesan, P. Sutton, and S. Wijffels, 2015: Unabated planetary warming and its ocean structure since 2006. Nat. Climate Change, 5, 240-245, https:// doi.org/10.1038/nclimate2513.

Roxy, M. K., K. Ritika, P. Terray, R. Murtugudde, K. Ashok, and B. N. Goswami, 2015: Drying of Indian subcontinent by rapid Indian Ocean warming and a weakening land-sea thermal gradient. Nat. Commun., 6, 7423, https://doi.org/10.1038/ncomms8423.

_- and Coauthors, 2016: A reduction in marine primary productivity driven by rapid warming over the tropical Indian Ocean. Geophys. Res. Lett., 43, 826-833, https://doi.org/ 10.1002/2015gl066979.

Saha, S., and Coauthors, 2010: The NCEP Climate Forecast System Reanalysis. Bull. Amer. Meteor. Soc., 91, 1015-1057, https:// doi.org/10.1175/2010BAMS3001.1.

Saji, N. H., B. N. Goswami, P. N. Vinayachandran, and T. Yamagata, 1999: A dipole mode in the tropical Indian Ocean. Nature, 401, 360-363, https://doi.org/10.1038/43854.

Schott, F. A., M. Dengler, and R. Schoenefeldt, 2002: The shallow overturning circulation of the Indian Ocean. Prog. Oceanogr., 53, 57-103, https://doi.org/10.1016/S0079-6611(02)00039-3.

—, S.-P. Xie, and J. P. McCreary Jr., 2009: Indian Ocean circulation and climate variability. Rev. Geophys., 47, RG1002, https://doi.org/10.1029/2007RG000245.

Schwarzkopf, F. U., and C. W. Böning, 2011: Contribution of Pacific wind stress to multi-decadal variations in upper-ocean heat content and sea level in the tropical south Indian Ocean. Geophys. Res. Lett., 38, L12602, https://doi.org/10.1029/2011GL047651.

Sérazin, G., B. Meyssignac, T. Penduff, L. Terray, B. Barnier, and J.-M. Molines, 2016: Quantifying uncertainties on regional sea level change induced by multidecadal intrinsic oceanic variability. Geophys. Res. Lett., 43, 8151-8159, https://doi.org/ 10.1002/2016GL069273. 
Shankar, D., S. G. Aparna, J. P. McCreary, I. Suresh, S. Neetu, F. Durand, S. S. C. Shenoi, and M. A. Al Saafani, 2010: Minima of interannual sea-level variability in the Indian Ocean. Prog. Oceanogr., 84, 225-241, https://doi.org/10.1016/j.pocean.2009.10.002.

Singh, D., 2016: South Asian monsoon: Tug of war on rainfall changes. Nat. Climate Change, 6, 20-22, https://doi.org/ 10.1038/nclimate2901.

Smith, D. M., and Coauthors, 2016: Role of volcanic and anthropogenic aerosols in the recent global surface warming slowdown. Nat. Climate Change, 6, 936-940, https://doi.org/10.1038/nclimate3058.

Sprintall, J., A. L. Gordon, A. Koch-Larrouy, T. Lee, J. T. Potemra, K. Pujiana, and S. E. Wijffels, 2014: The Indonesian seas and their role in the coupled ocean-climate system. Nat. Geosci., 7, 487-492, https://doi.org/10.1038/ngeo2188.

Srinivasu, U., M. Ravichandran, W. Han, S. Sivareddy, H. Rahman, Y. Li, and S. Nayak, 2017: Causes for the reversal of north Indian Ocean decadal sea level trend in recent two decades. Climate Dyn., 49, 3887-3904, https://doi.org/10.1007/s00382-017-3551-y.

Sura, P., M. Newman, and M. A. Alexander, 2006: Daily to decadal sea surface temperature variability driven by state-dependent stochastic heat fluxes. J. Phys. Oceanogr., 36, 1940-1958, https://doi.org/10.1175/JPO2948.1.

Swapna, P., J. Jyoti, R. Krishnan, N. Sandeep, and S. M. Griffies, 2017: Multidecadal weakening of Indian summer monsoon circulation induces an increasing northern Indian Ocean sea level. Geophys. Res. Lett., 44, 10 560-10 572, https://doi.org/ 10.1002/2017GL074706.

Thompson, P. R., C. G. Piecuch, M. A. Merrifield, J. P. McCreary, and E. Firing, 2016: Forcing of recent decadal variability in the equatorial and north Indian Ocean. J. Geophys. Res. Oceans, 121, 6762-6778, https://doi.org/10.1002/2016JC012132.

Tozuka, T., T. Kataoka, and T. Yamagata, 2014: Locally and remotely forced atmospheric circulation anomalies of Ningaloo Niño/Niña. Climate Dyn., 43, 2197-2205, https://doi.org/ 10.1007/s00382-013-2044-x.

Trenary, L. L., and W. Han, 2013: Local and remote forcing of decadal sea level and thermocline depth variability in the south Indian Ocean. J. Geophys. Res. Oceans, 118, 381-398, https://doi.org/10.1029/2012JC008317.

Trenberth, K. E., and J. T. Fasullo, 2010: Tracking Earth's energy. Science, 328, 316-317, https://doi.org/10.1126/science.1187272. , and - 2012: Tracking Earth's energy: From El Niño to global warming. Surv. Geophys., 33, 413-426, https://doi.org/ 10.1007/s10712-011-9150-2.

, and _ 2013: An apparent hiatus in global warming? Earth's Future, 1, 19-32, https://doi.org/10.1002/2013EF000165.
Ummenhofer, C. C., A. Biastoch, and C. W. Böning, 2017: Multidecadal Indian Ocean variability linked to the Pacific and implications for preconditioning Indian Ocean dipole events. J. Climate, 30, 1739-1751, https://doi.org/10.1175/JCLI-D-16-0200.1.

UNFCCC Conference of the Parties, 2015: Adoption of the Paris Agreement. FCCC/CP/2015/10/Add.1 Rep., 36 pp., https:// unfccc.int/resource/docs/2015/cop21/eng/10a01.pdf.

Wang, G., L. Cheng, J. Abraham, and C. Li, 2018: Consensuses and discrepancies of basin-scale ocean heat content changes in different ocean analyses. Climate Dyn., 50, 2471-2487, https:// doi.org/10.1007/s00382-017-3751-5.

Wernberg, T., D. A. Smale, F. Tuya, M. S. Thomsen, T. J. Langlois, T. de Bettignies, S. Bennett, and C. S. Rousseaux, 2013: An extreme climatic event alters marine ecosystem structure in a global biodiversity hotspot. Nat. Climate Change, 3, 78-82, https://doi.org/10.1038/nclimate1627.

Wijffels, S., and G. Meyers, 2004: An intersection of oceanic waveguides: Variability in the Indonesian Throughflow region. J. Phys. Oceanogr., 34, 1232-1253, https://doi.org/10.1175/ 1520-0485(2004)034<1232:AIOOWV >2.0.CO;2.

Wirth, A., J. Willebrand, and F. Schott, 2002: Variability of the Great Whirl from observations and models. Deep-Sea Res. II, 49, 1279-1295, https://doi.org/10.1016/S0967-0645(01)00165-5.

Xie, S.-P., 2016: Oceanography: Leading the hiatus research surge. Nat. Climate Change, 6, 345-346, https://doi.org/10.1038/ nclimate2973.

Yu, L., and R. A. Weller, 2007: Objectively analyzed air-sea heat fluxes for the global ice-free oceans (1981-2005). Bull. Amer. Meteor. Soc., 88, 527-539, https://doi.org/10.1175/ BAMS-88-4-527.

Zhang, L., W. Han, and F. Sienz, 2018: Unraveling causes for the changing behavior of the tropical Indian Ocean in the past few decades. J. Climate, 31, 2377-2388, https://doi.org/10.1175/ JCLI-D-17-0445.1.

Zhuang, W., M. Feng, Y. Du, A. Schiller, and D. Wang, 2013: Low-frequency sea level variability in the southern Indian Ocean and its impacts on the oceanic meridional transports. J. Geophys. Res. Oceans, 118, 1302-1315, https://doi.org/10.1002/ jgrc. 20129

Zinke, J., and Coauthors, 2015: Coral record of southeast Indian Ocean marine heatwaves with intensified western Pacific temperature gradient. Nat. Commun., 6, 8562, https://doi.org/ $10.1038 /$ ncomms 9562.

Zweng, M. M., and Coauthors, 2013: Salinity. Vol. 2, World Ocean Atlas 2013, NOAA Atlas NESDIS 74, 39 pp., http://data.nodc.noaa.gov/ woa/WOA13/DOC/woa13_vol2.pdf. 